\title{
THE DIALECTS LANGUAGES AND ARAB WORDS CITED BY ALSAHEB BIN ABBAD (D. 385 H) IN AL-MUHEET'S DICTIONARY OF THE LANGUAGE
}

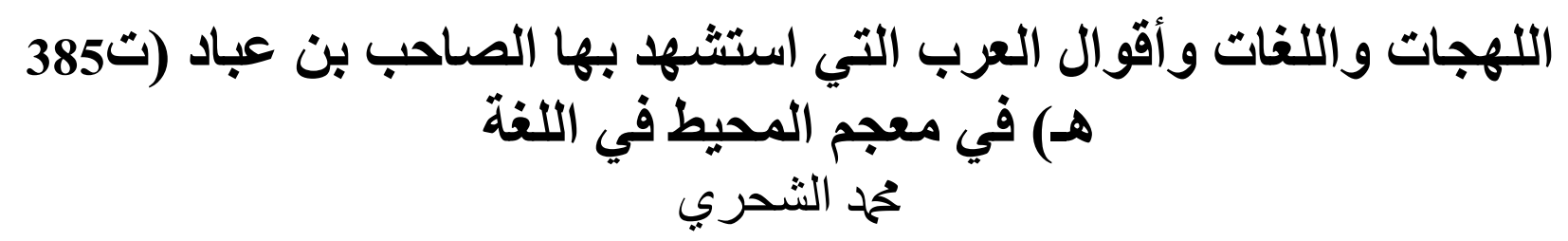

\author{
Mohammed Albakhit Said Alshahri ${ }^{1 *}$, Prof. Dr. Majdi Haji Ibrahim ${ }^{2} \&$ \\ Prof. Dr. Asem Shehadeh $\mathrm{Ali}^{3}$
}
${ }^{1}$ Ph.D. Candidate kuliyah of Knowledge, Revelation and Humanities at International Islamic University Malaysia (IIUM), m99482010@gmail.com
${ }^{2}$ Prof. Dr. Assoc. kuliyah of Knowledge, Revelation and Humanities at International Islamic University Malaysia (IIUM), majdi@iium.edu.my
${ }^{3}$ Prof. Dr. Assoc. kuliyah of Knowledge, Revelation and Humanities at International Islamic University Malaysia (IIUM), muhajir4@iium.edu.my
${ }^{*}$ Corresponding Author

\begin{abstract}
This study follows the languages and dialects mentioned and cited by Ibn Abbad in his surrounding dictionary on the language, and an analytical study of the materials and explanations that were scattered throughout the dictionary. The problem lies in the fact that the studies that were discussed and stood on the book "The Lexicon of the Ocean in Language" did not record the approach used by Ibn Abbad in the topics and issues that he brought up between the books of his lexicon, as this aspect did not receive an in-depth and careful study. Therefore, the study aims to: Explain his method in citing dialects and languages, and present his method in citing poetic evidence and sayings of the Arabs. Through the descriptive method, analysis, explanation and statistics, the study reached the following results: The mention of the various Arabic dialects has made the Arabic dialects within the ocean dictionary in the language an entity worthy of study and analysis. Al-Saheb bin Abbad was martyred during his explanation of the materials for many languages and dialects, as the most roses were Hudhayl's language 40 times, then the people of Yemen 34 times, the language of the people of Persia 28 times and the language of Hamir 20 times. Al-Saheb Bin Abbad reduced his citation to Arabic poetry.
\end{abstract}

Keywords: languages, dialects, sayings of the Arabs, ocean dictionary in the language.

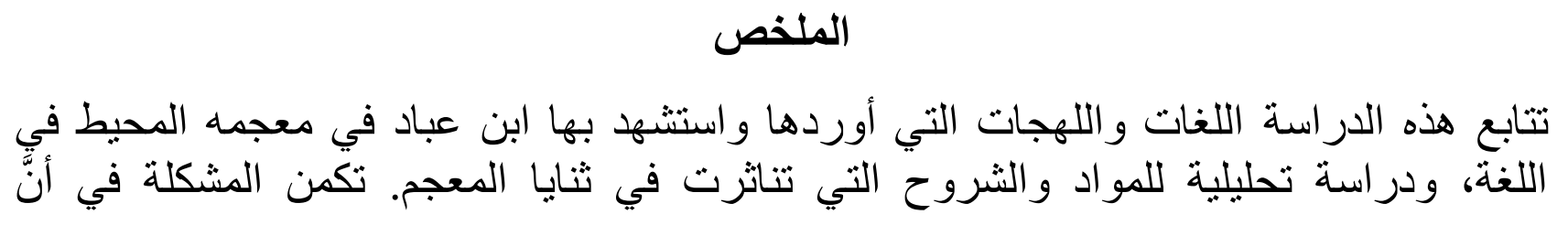


الدراسات التي ناقتت ووققت على كتاب معجم المحيط في اللغة؛ لم تستجل المنهج الذي استعمله

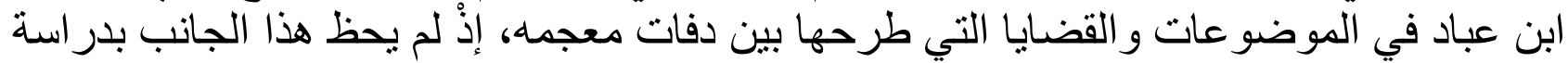

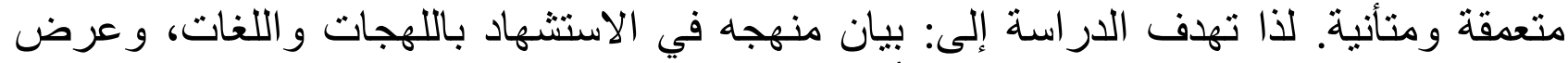

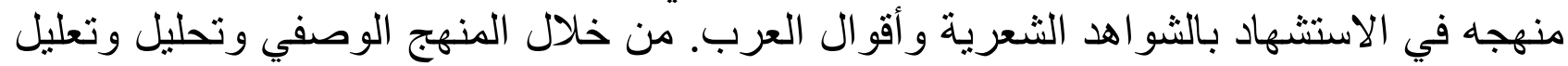

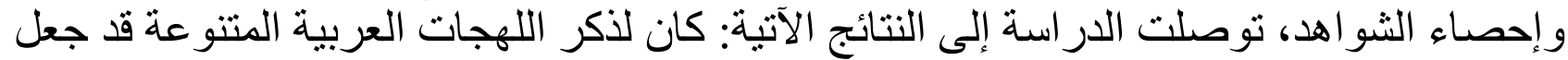

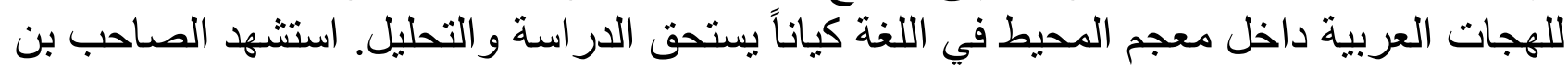

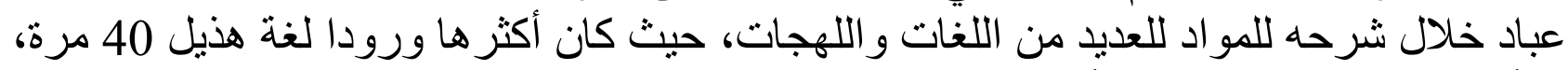

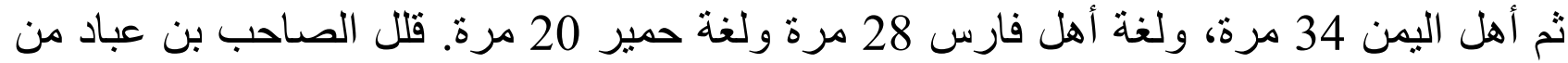
الاستشهاد بالأشعار العربية. كلمات مفتاحية: اللغات، و اللهجات، ألقو ال العرب، معجم المحيط في اللغة.

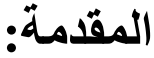

ابن عباد هو الصاحب كافي الكفاة أبو القاسم، إسماعيل بن عباد بن العباس بن أحمد بن إدريس،

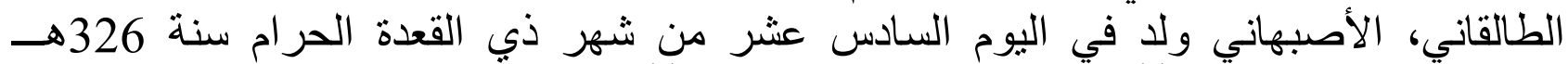

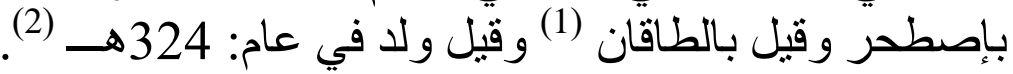

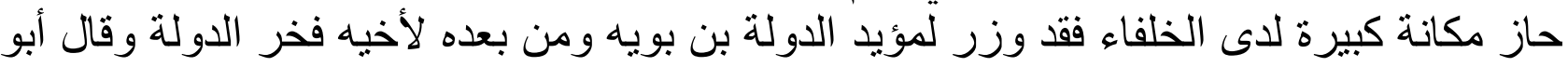

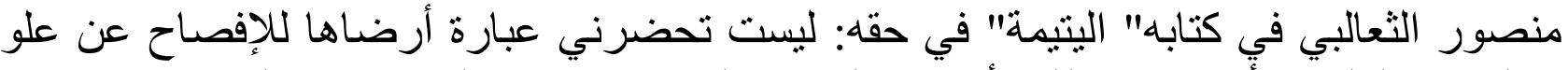

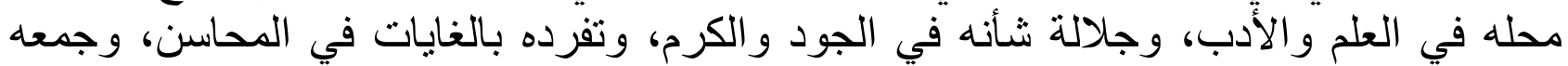

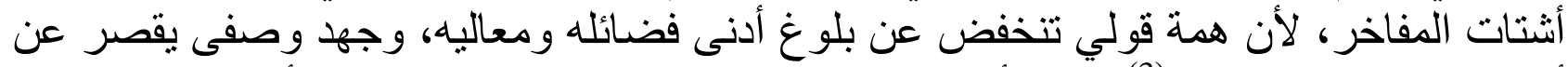

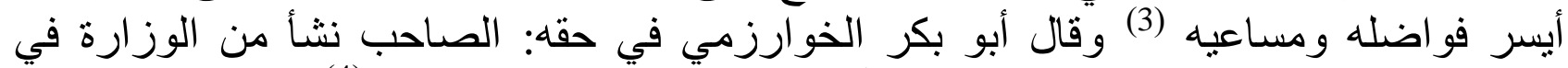

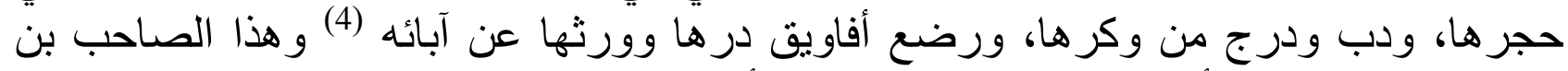

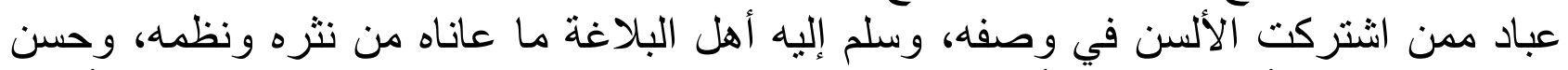

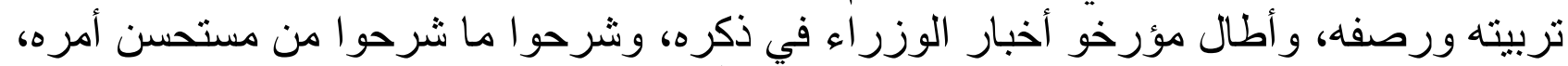

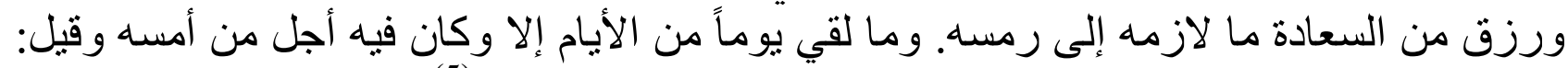

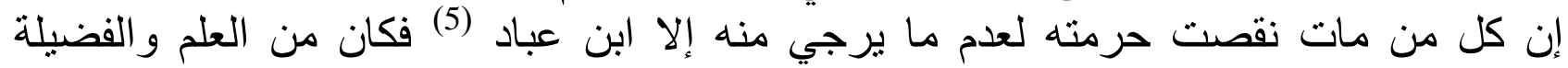

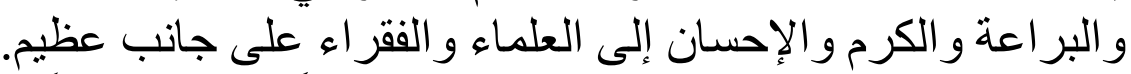

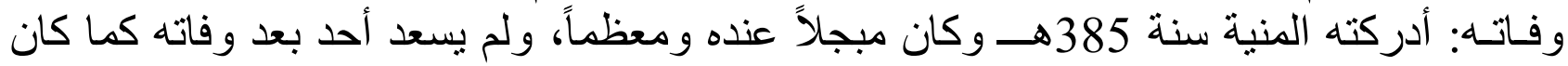

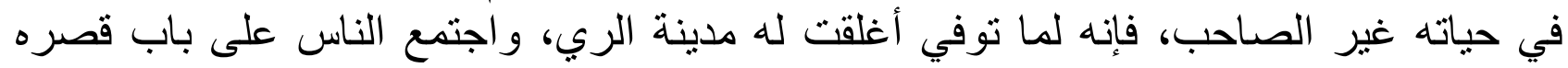

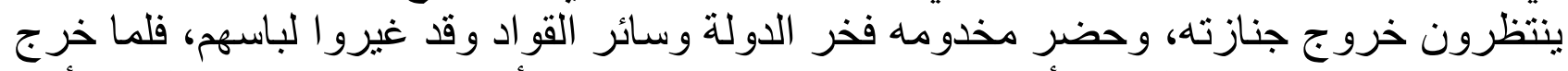

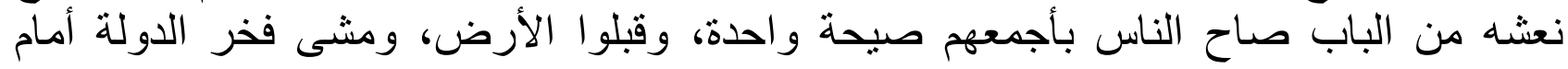

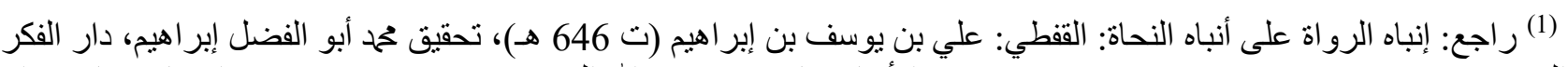

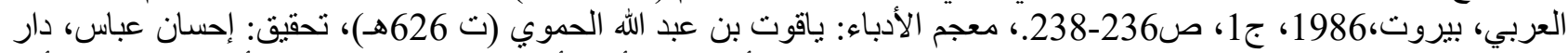

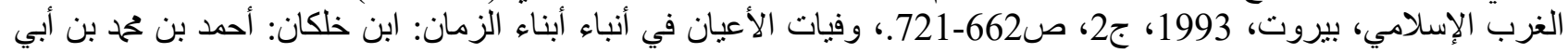

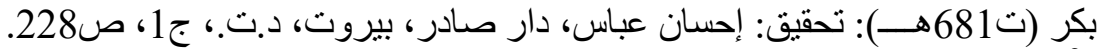

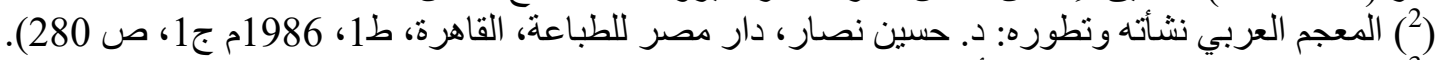

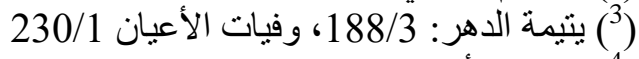
230/1: وفيات الأعيان 237/1: إنباه الرواة على أنباء النحان 
الجنازة مع الناس، وقعدو اللعز اء أباما (6).

\section{التعريف بمعجم المحيط في اللغة:}

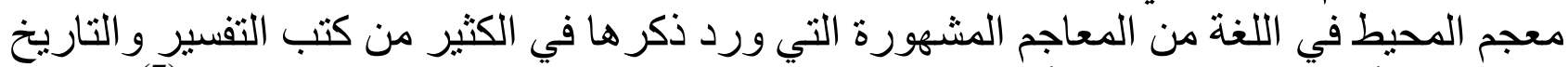

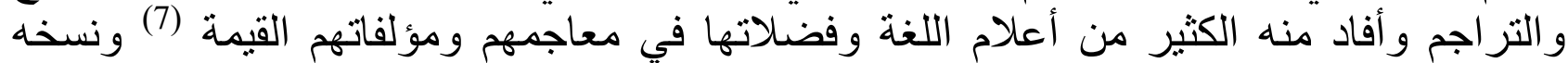

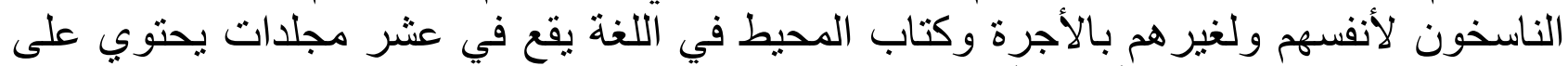

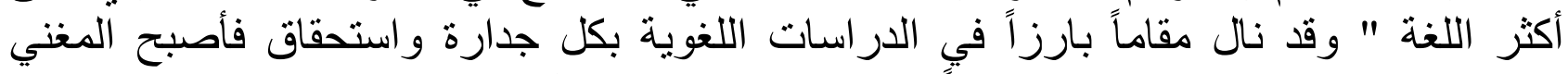

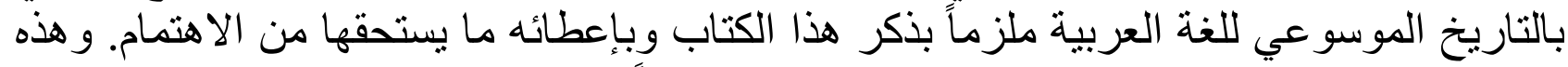

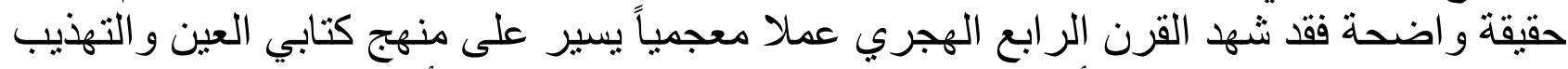

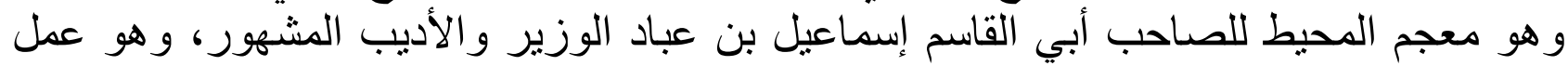

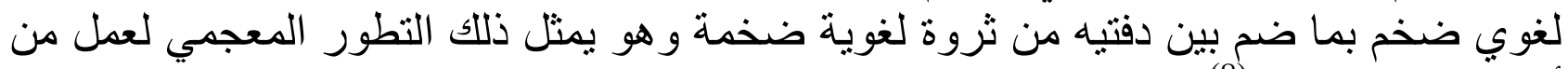

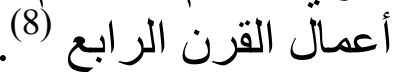

مشكلة الدراسة:

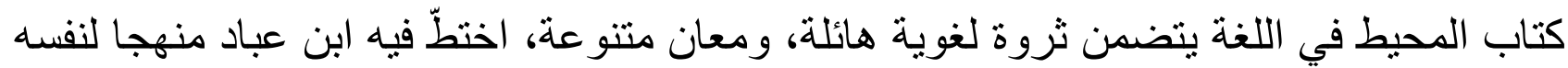

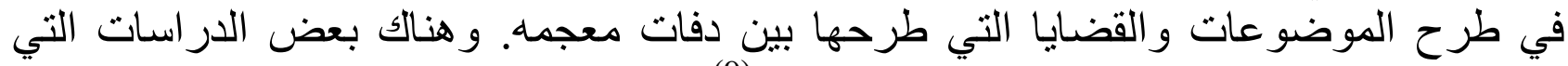

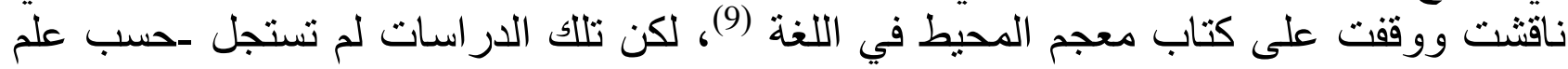

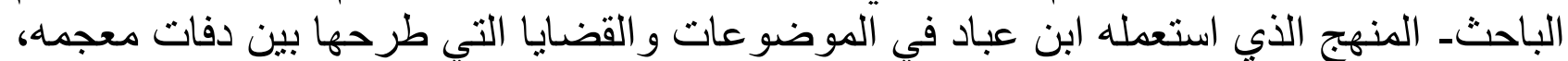
إذْ لم يحظ هذا الجانب بدر استة متعدقة ومنأنية.

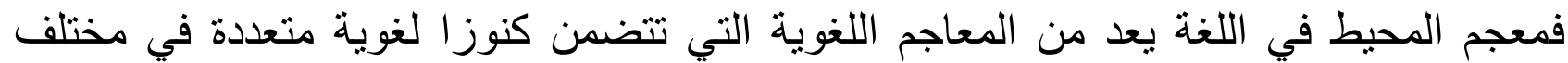

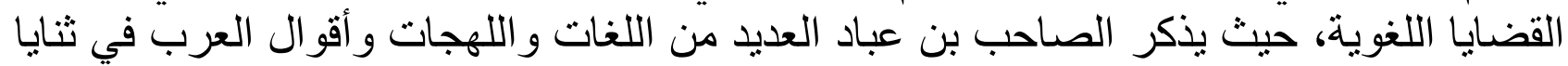

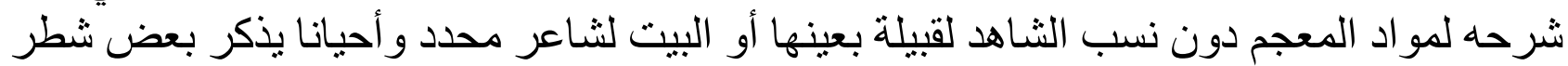

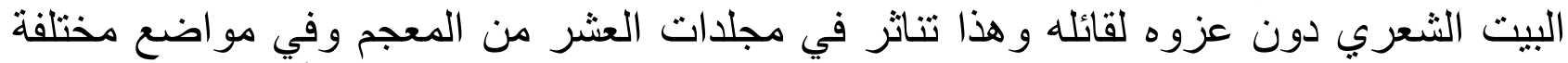

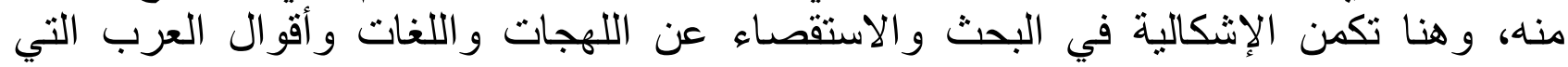

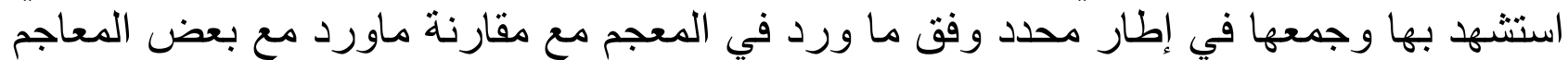

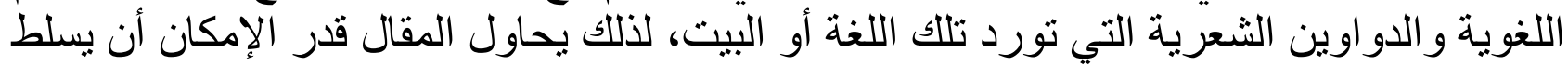

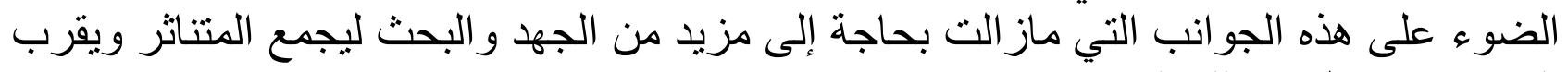
المتشرد ويربط بين تللك الثو الهد.

لذلك فهذا الكتاب بحاجة إلى بحث لار اسة اللهجات و اللغات التي وردت في المعجم، ومعرفة

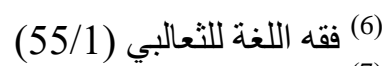

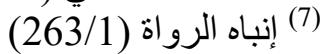

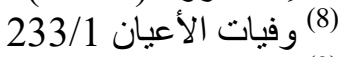

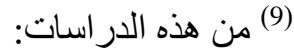

ـ دراسات لهجية في المحيط لابن عباد، الجزء الأول المستوى الصوتي، مجلة كلية اللغة العربية ـ العدد الرابع والعشرون ـ

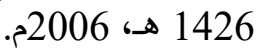
ـ ـ الدعجم العربي: نشأته وتطوره، للاكتور حسين نصار ، القاهرة.

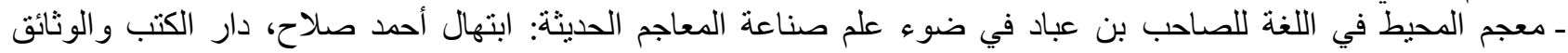

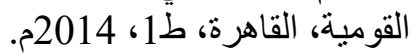


الأشعار الذي شرح بها المؤلف مواده، وكيف تعامل مع القضايا اللغوية والنحوية والفقهية

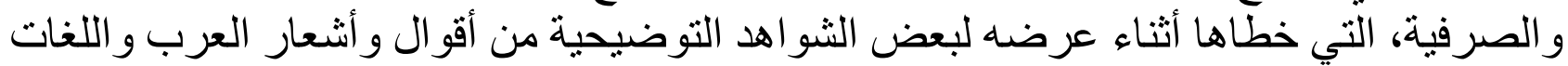
و اللهجات.

\section{أهداف الاراسة:}

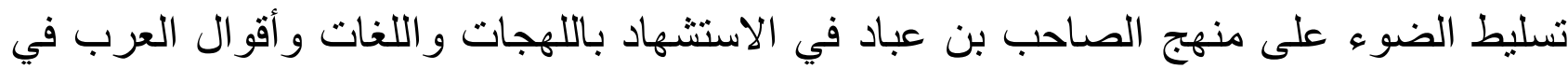

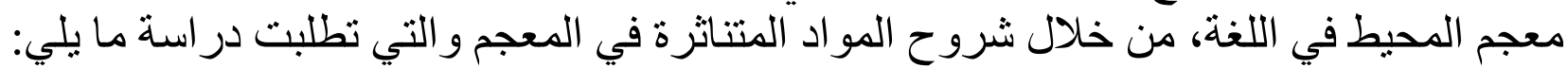
أ. بيان منهجه في الاستشهاد باللهجات و اللغات ب. عرض منهجه في الاستشهاد بالثو اهد الثعرية و أقو ال العرب.

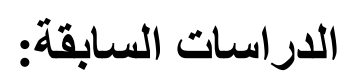

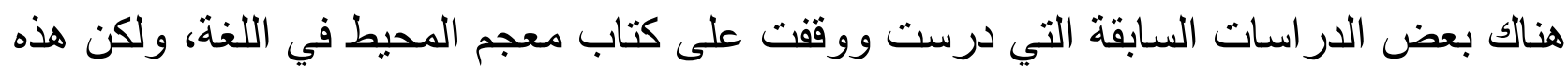

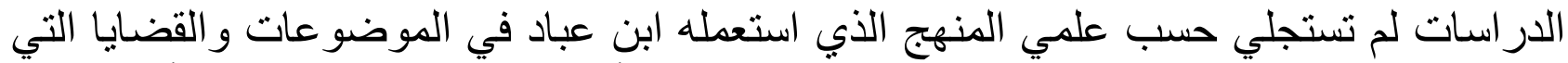

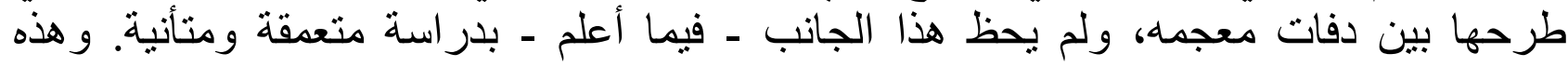

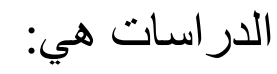

دراسة للاكتور حسين نصار بعنوان: المعجم العربي: نشأته وتطوره. حيث تحدثت الدراسة

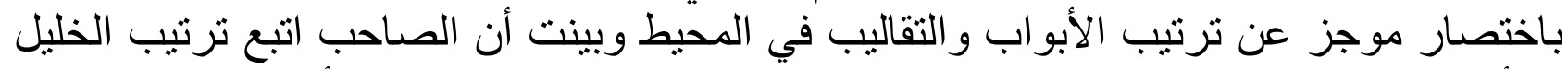

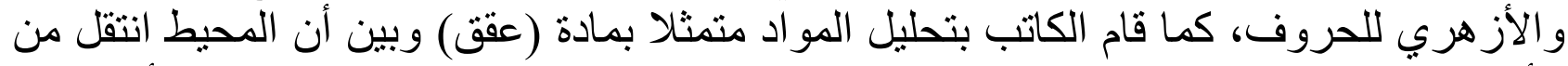

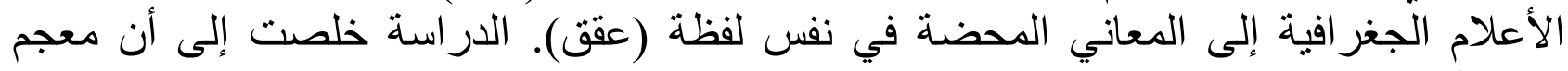

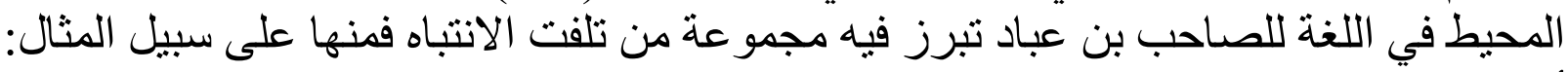
أ. ظاهرة الاختصار و عدم الاستقصاء.

ب. انفر اده بكثرة الصيغ و الألفاظو المعاني التي لا نوجد عند غيره من مؤلفي المعاجم. ت. ات. اهمامه بالعبار ات المجازية.

ولم تتطرق الدر اسة إلى أي تفصيل يتعلق باللهجات أو اللغات أو الثو اهد الثعرية التي ذكر ها ابن عباد في مؤلفه معجم المحيط في اللغة.

معجم المحيط في اللغة للصاحب بن عباد في ضوء إه علم صناء صناعة المعاجم الحديثة: توصلت الباحثة

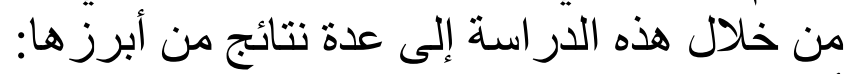

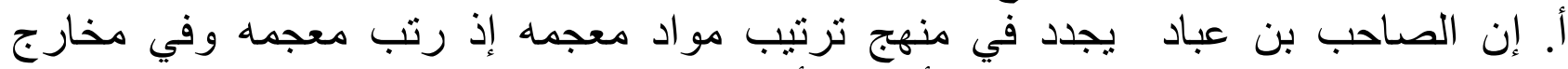

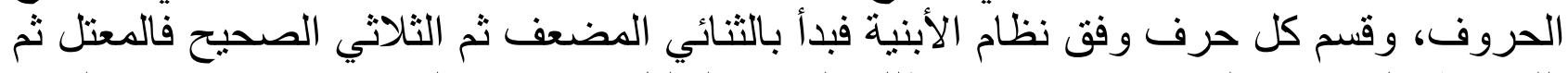

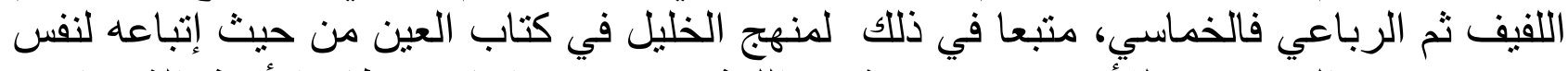

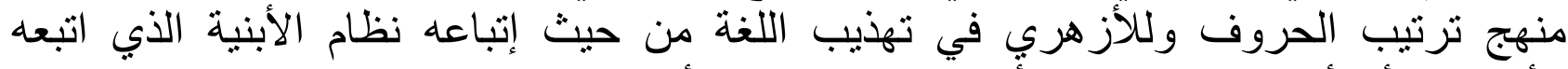
الأزهري، أبي أن ابن عباد لم يقدم أبي منهج جديد في فئ التأليف. ب. لم يقف ابن عباد في معجمه عند حدود التفسيرات اللغوية للألفاظ بل إنه عالج في كثير من 


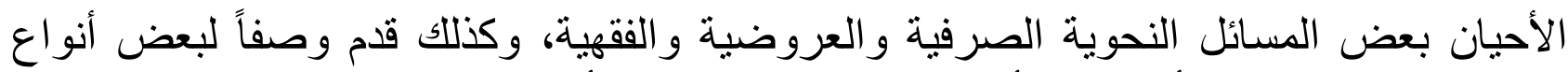

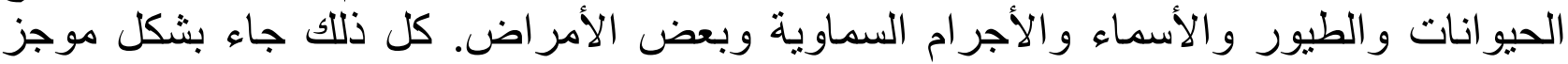
ومبسط لا يحل بوظيفة المعجم الأساسية.

ت. لم يتبع منهجاً محدداً في شروح مو اد معجمه فجاءت الألفاظ والصيغ متداخلة فلا يوجد تقديم

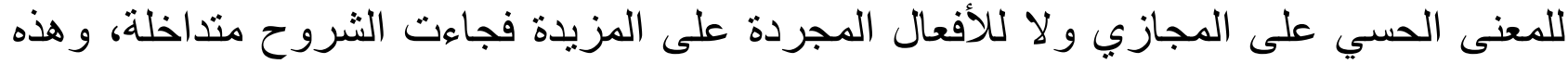
هي سمة المعاجم اللغوية القديمة.

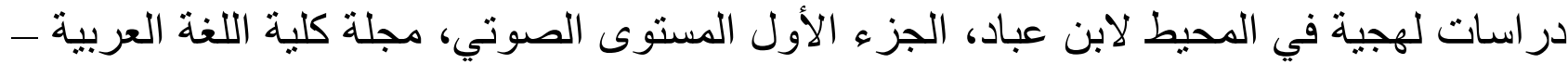

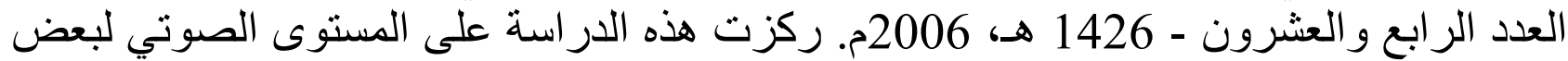

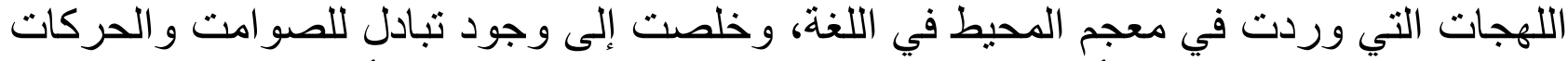

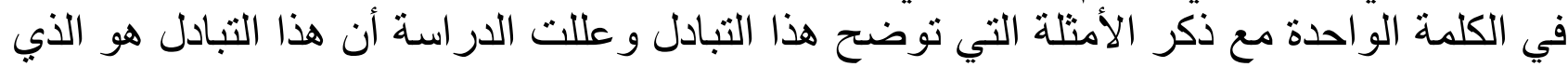
يؤدي إلى اختلاف اللهجات بين القبائل.

منهج الاراسة:

المنهج المتبع هو المنهج الوصفي، ويجنح إلى التحليل والتعليل، والإحصاء في حدود الإمكان، وبما يتطلبه المقام. إن منهج الصاحب في الاستشهاد باللهجات واللغات قد تطلب دراسته وفق الإن اللقان

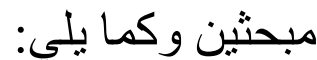

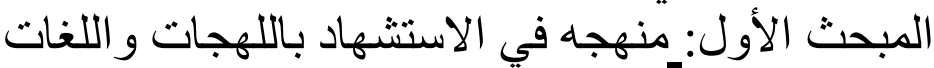

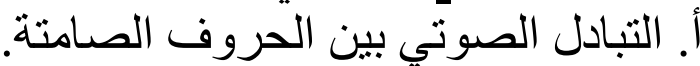

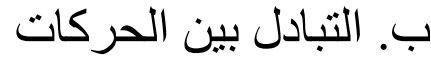

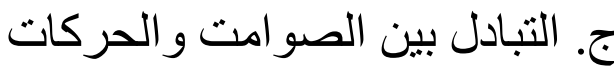

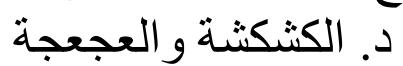

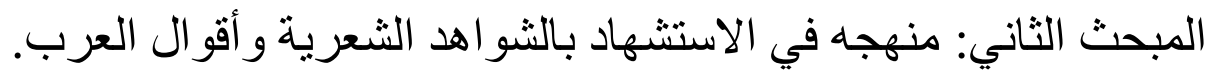
أ. أبيات شعرية كاملة منسوبة لقانيات لقائليها: ب. أبيات شعرية كاملة غير منسوبة فئة لقائليها: ج. أشطار شعرية منسوبة لقائليها: د. أثنطار شعرية غير منسوبة لقائلئها:

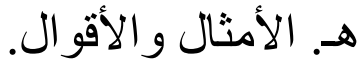

المبحث الأول: منهجه في الاستشهاد باللهجات واللغات

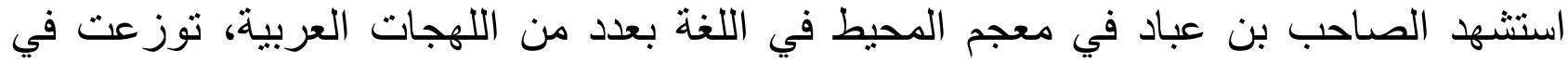

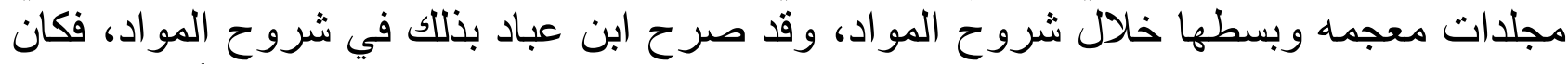

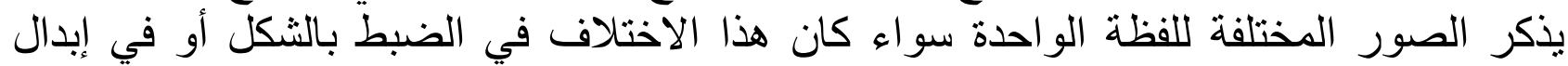

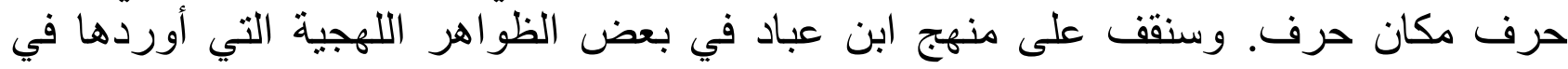

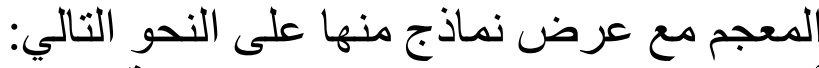

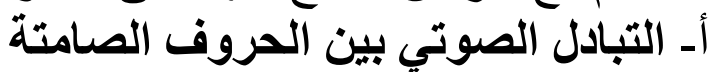
لقد ساق ابن عباد عدداً كبيراً من هذه الهُ الألفاظ دون أن أن يلعق عليها أو يفسر سبب الإبدال بين هذه

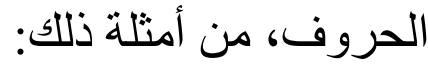


تحدث ابن عباد عن لهجة مشهورة في اللهجات العربية وبين التغير الصوتي الذي يحدث في هذه

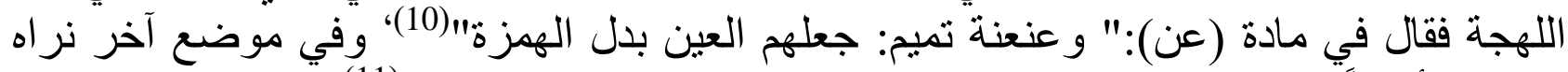

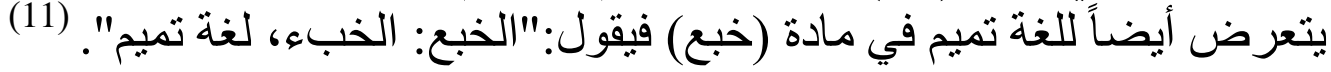

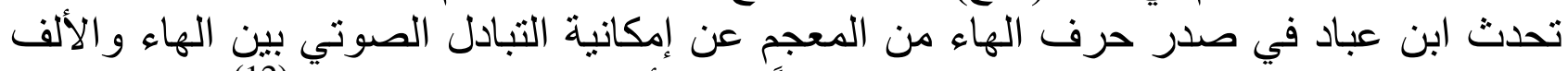

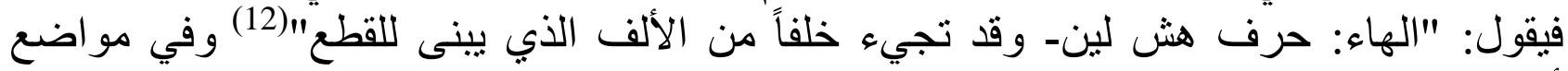

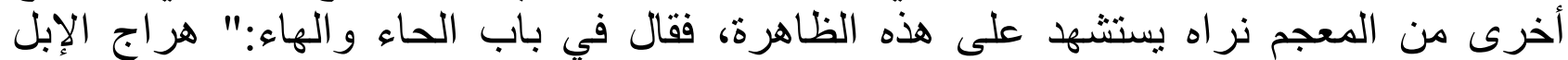

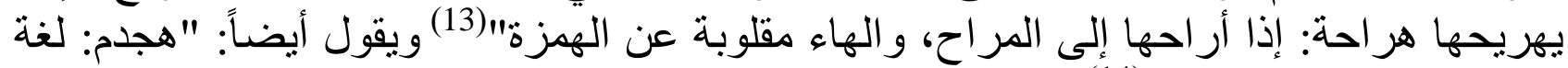

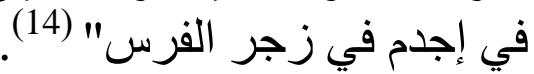

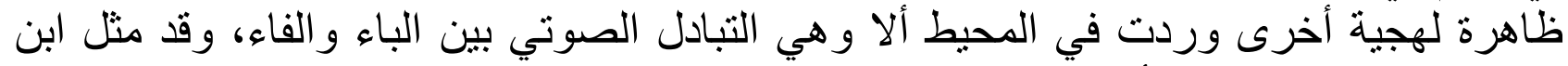

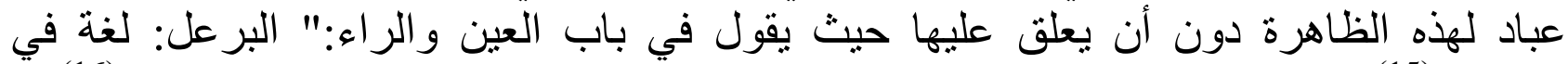

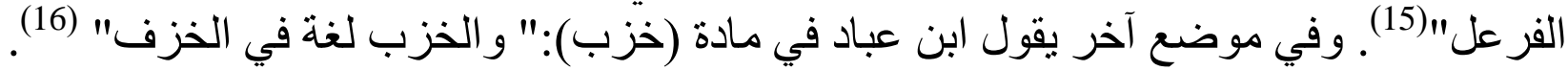

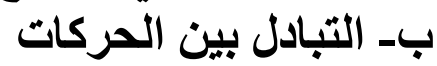

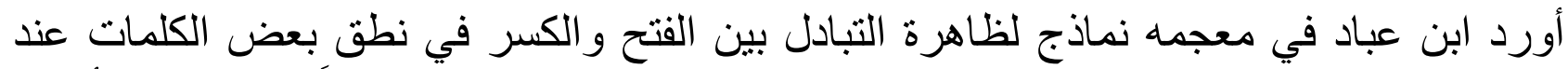

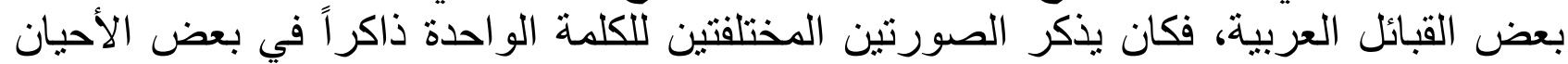

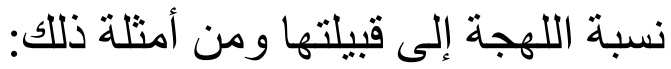

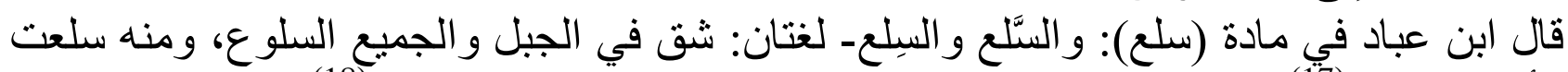

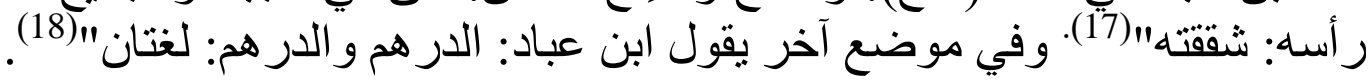
وفي مادة (حلق) يمثل ابن عباد لهذه الظاهرة منسوبة إلى قبيلة بلحرث الثرثن قائلاً:" وحلقة الباب،

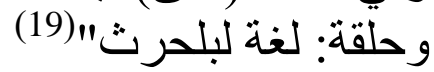
وأورد ابن عباد مثالاً آخر لهذه الظاهرة في مادة (شهد) إذ يقول:" وشهد فلان بحق فلان شـادة، فلو

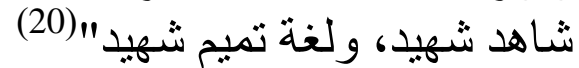
أورد ابن عباد في معجمه نماذج للتبادل بين القتح و الضم في في بعض التهان الكلمات و التي نشأ عنها

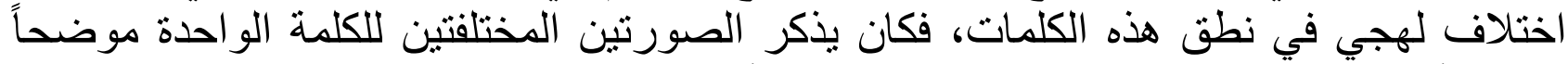

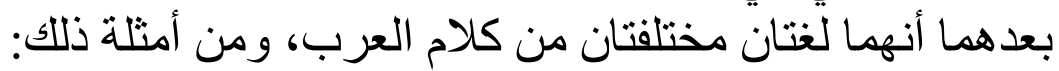

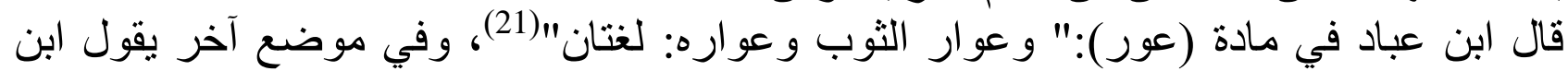

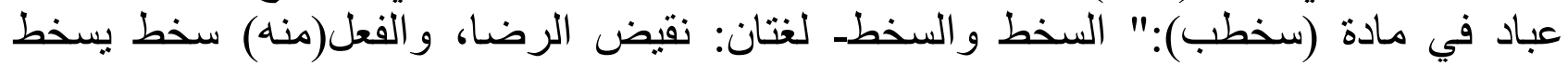

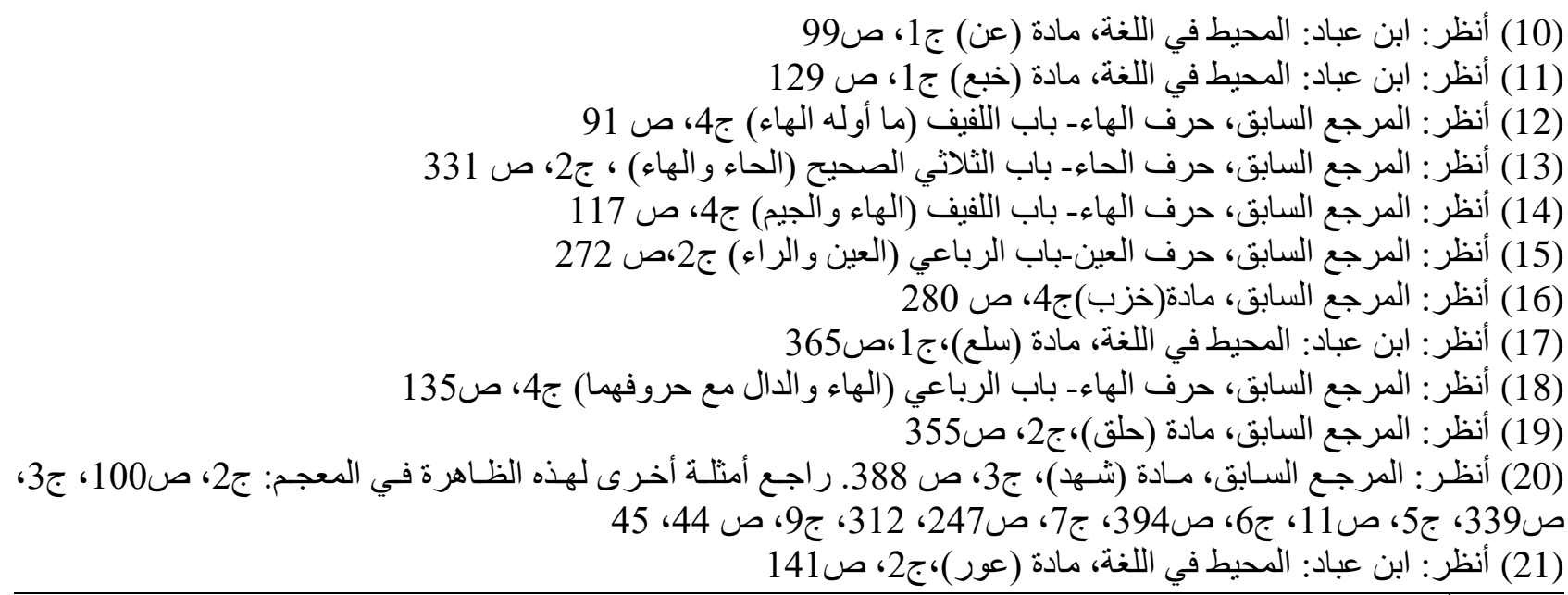


ويتسخط" (22).

ونجد ابن عباد أيضاً يقول في مادة (رفغ):" والرفغ والرفغ- لغتان: باطن الفخذ عند الأربية"(23)

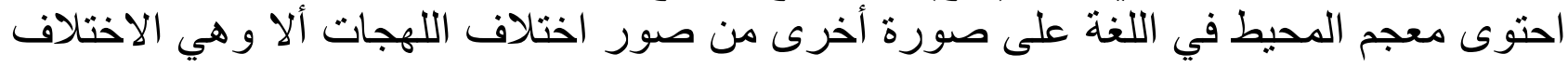

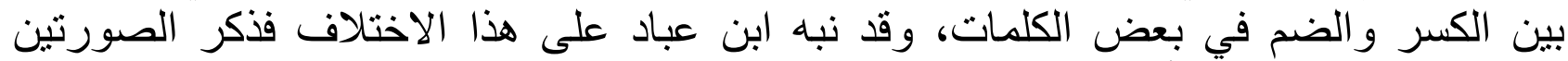
المختلفتين للكلمة موضحاً أنهما لغتان من لغات العرب ودن ون أمثلة ذلك في المعجم:

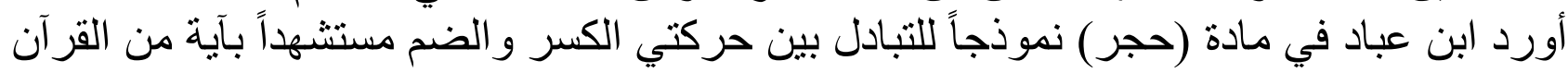

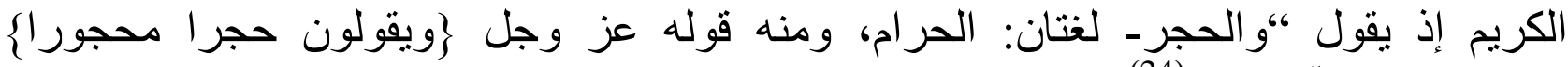

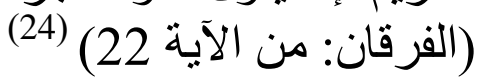

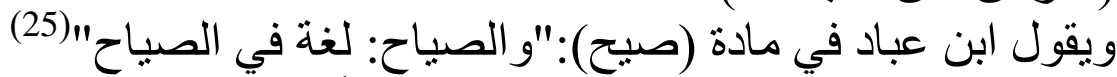

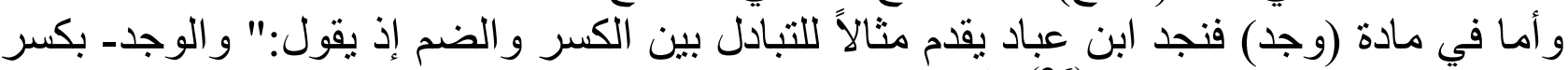

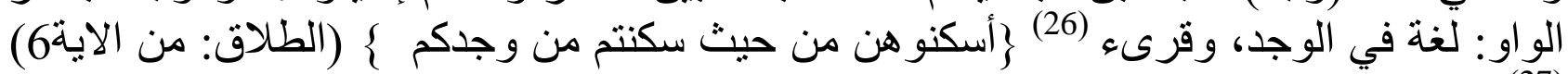

من الظو اهر اللهجية التي وردت في المحيط في اللغة ظاهرة التبادل بين الفتح والكسر و الضم في الكلمة الواحدة، فكان ابن عباد يذكر الكلمة الواحدة بصور ها التثلاثة منبهاً على ذلك في ثنايا شرح

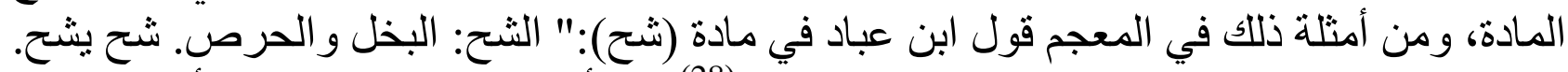

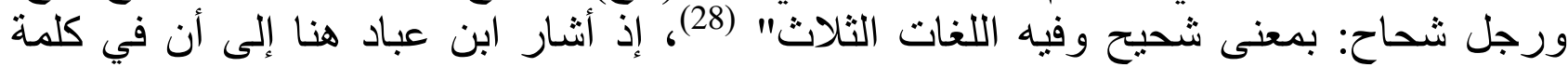

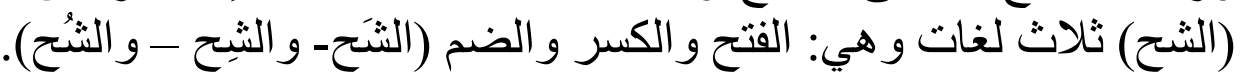
وفي موضع آخر ذكر الصور الثثلاثنة للكلمة الواحدة فيقول في مادة (وجن):" الوجنة: ما ارتفع من

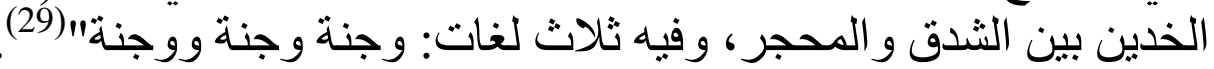

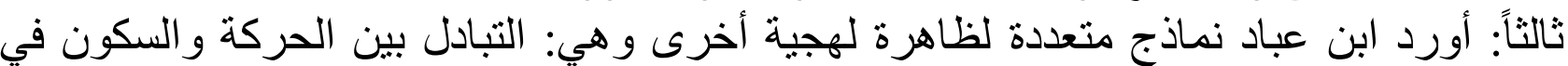

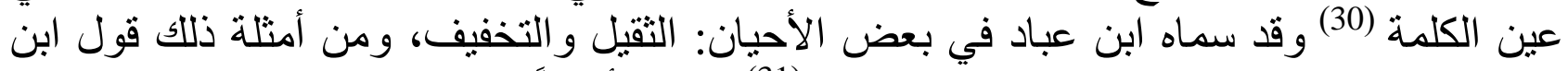

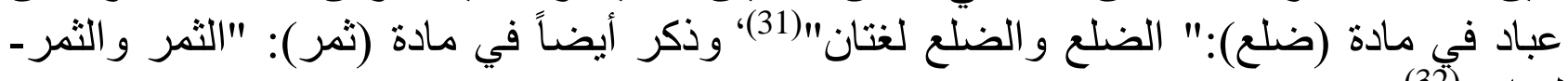
لغتان" (32) و أورد ابن عباد في مادة (معد) مثالاً للتبادل بين الكسر و السكون. حيث قال: ،“المعدة لغة في المعدة" (33).

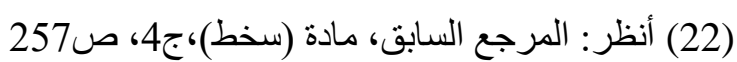

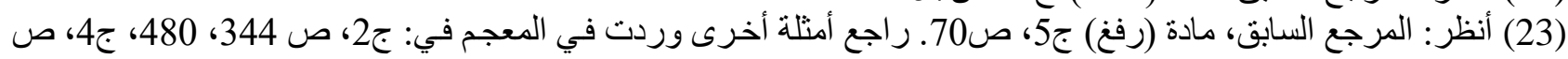

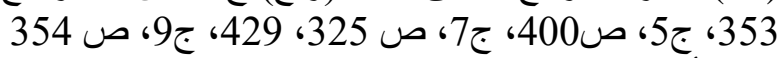

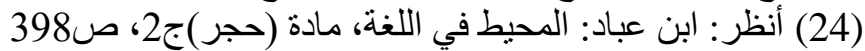

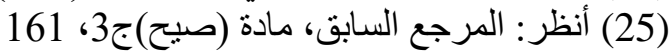

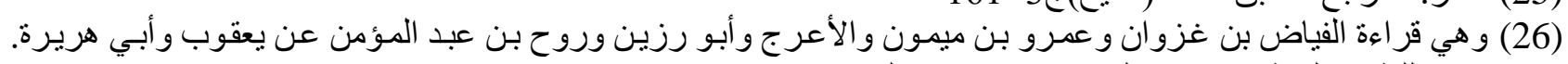

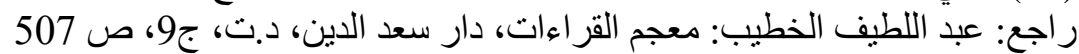

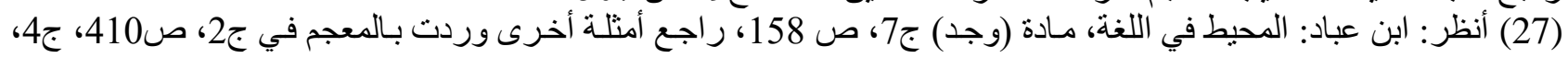


ج- التبادل بين الصوامت والحركات.

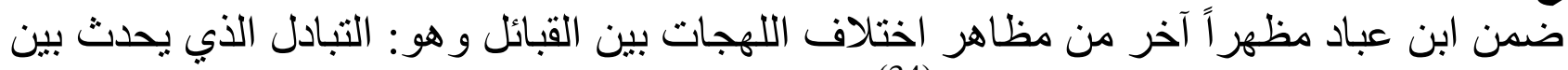

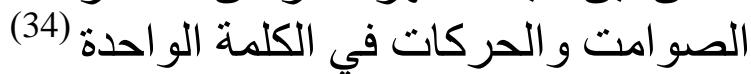

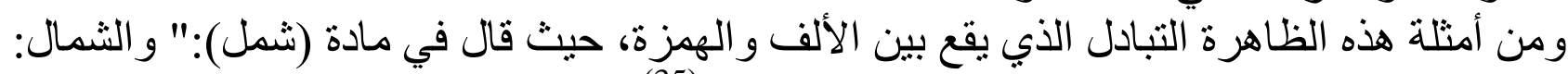

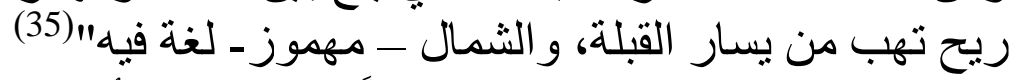

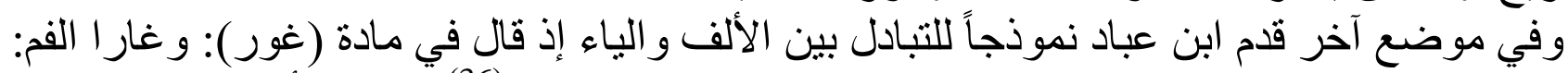

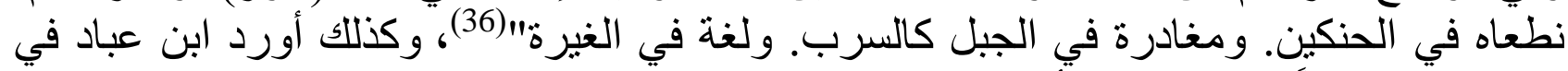

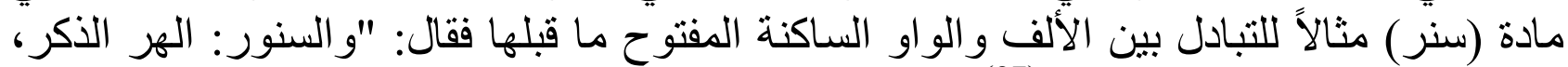

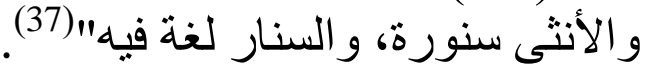

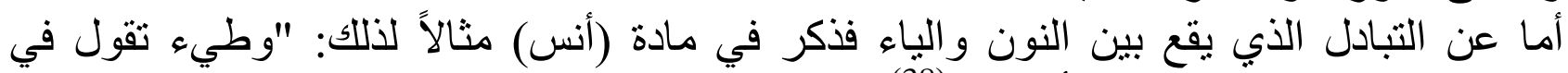

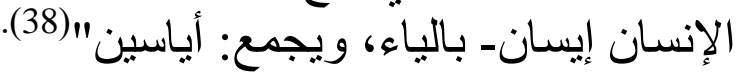

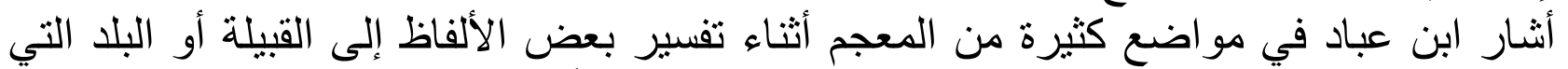

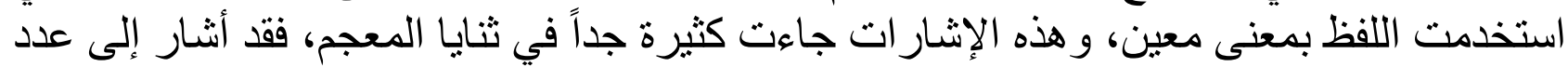

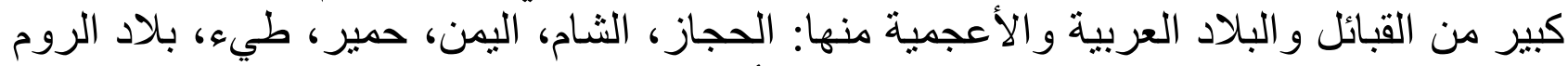

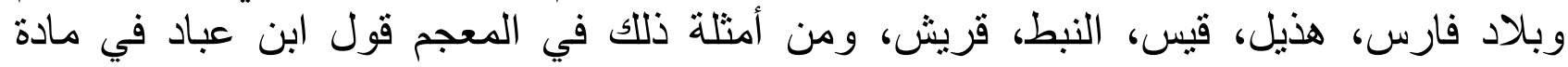

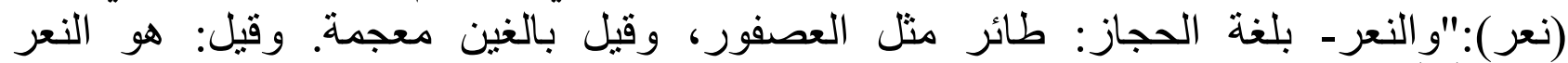
(أيضاً")( وقال ابن عباد أيضاً: الكعسوم والعكموس: الحمار؛ بلغة حمير"(40)، وفي مادة (زقد) يقول ابن

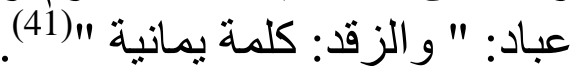

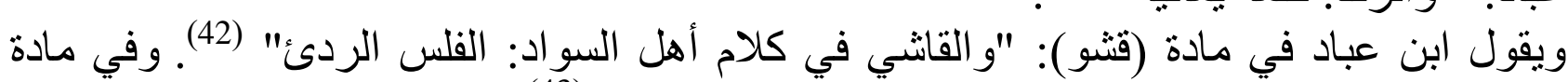

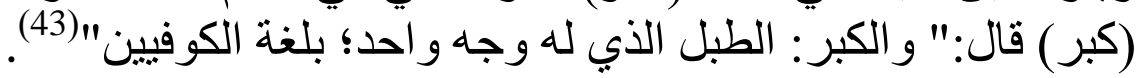

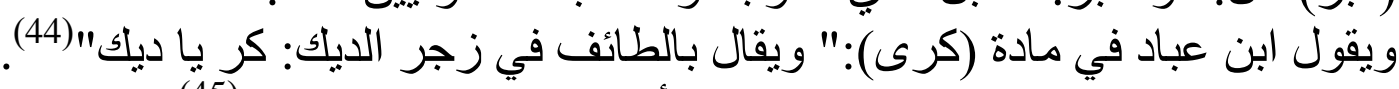

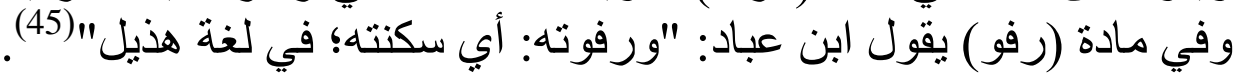

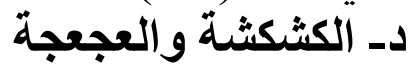
من الظو اهر اللهجية التي تحدثة عنها التها ابن عباد في معجمه ظاهرة الكثكثة وقد فسر هذه الظكاهرة بقوله: " و الكشكثة: لغة لربيعة يقولونها عند كاف التأنيث، نحو عليكث وبكش وبحة وبحر لا يكثكش:

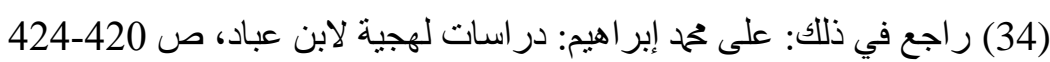

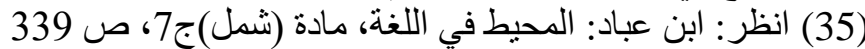

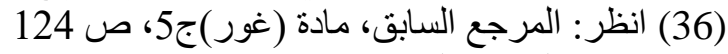

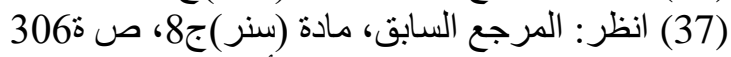

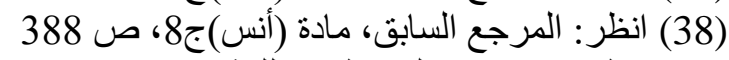

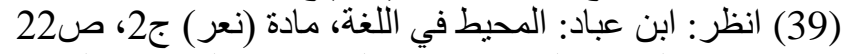

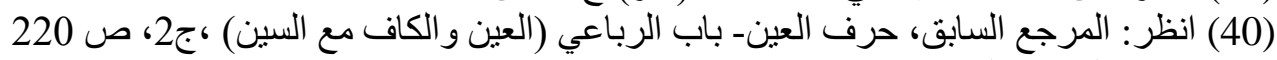

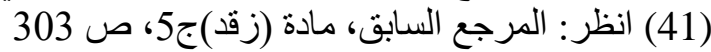

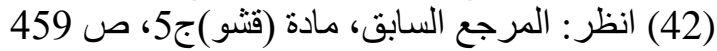

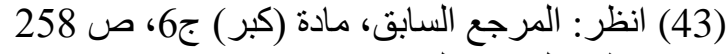

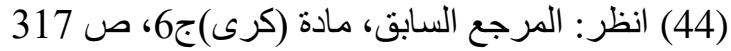

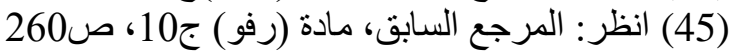

(5) انظر : معجم المحيط في اللغة للصاحب بن عباد في ضوء علم صناعة المعاجم الحديثة، ص 168-170. 
أي لا ينز ح"(46)، وقد نسب بعض العلماء الكثكثة إلى غير قبيلة، فنسبها الفيروز أبادى (47) لبني

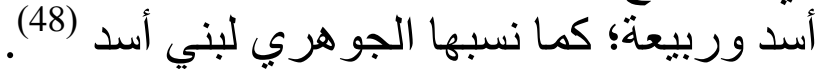

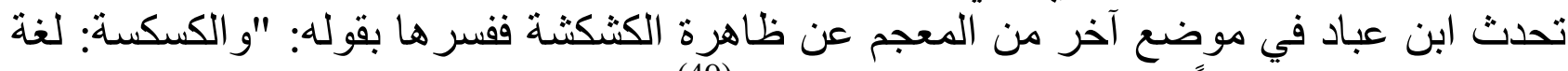

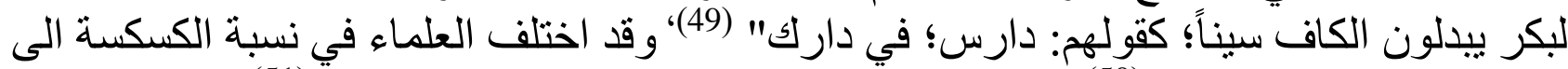

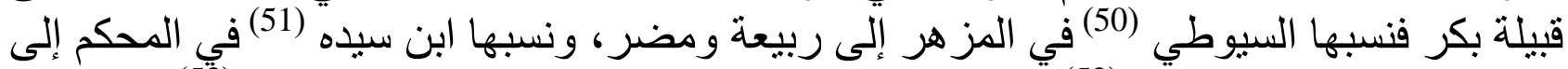

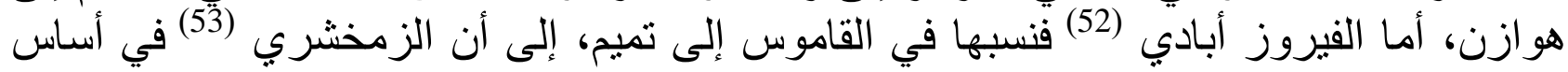

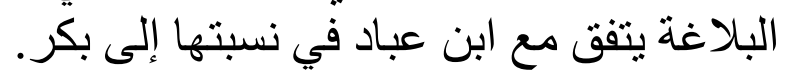

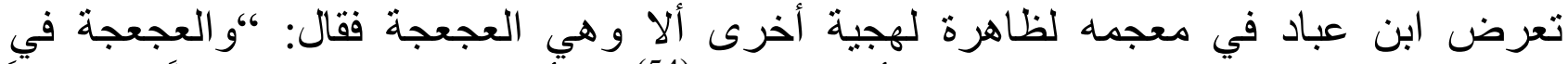

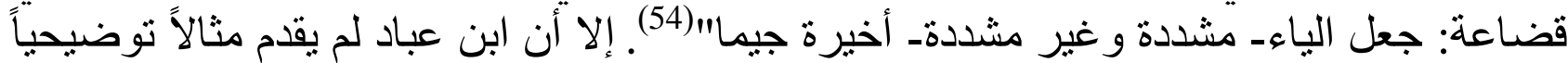

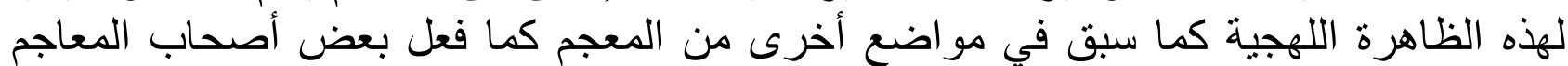

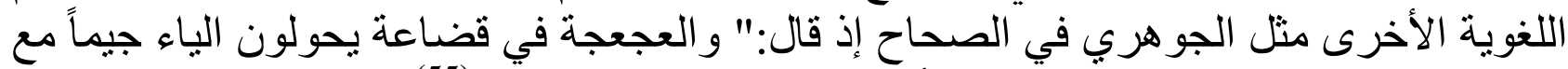

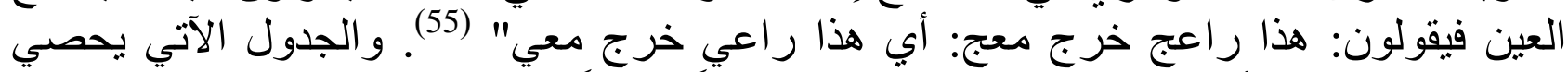
اللغات و اللهجات الأكثر ورودا بالمعجم، مرتبة ترنياً تنازلياً حسب مرات ورودها في صفحات المعجم

جدول (1) اللغات و اللهجات الأكثر ورودا بالمعجم

\begin{tabular}{|c|c|c|}
\hline مرات ورودها & اللغة & p \\
\hline 40 & هذيل & 1 \\
\hline 34 & أهل البمن & 2 \\
\hline 28 & الفارسية & 3 \\
\hline 20 & حمير & 4 \\
\hline 17 & طيء & 5 \\
\hline 12 & العجم & 6 \\
\hline 10 & أهل العراق & 7 \\
\hline 9 & أهل الحجاز & 8 \\
\hline 6 & أهل عمان & 9 \\
\hline 5 & العامة & 10 \\
\hline
\end{tabular}

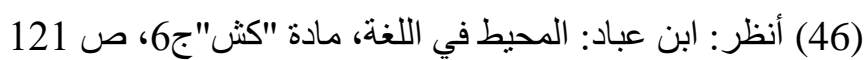

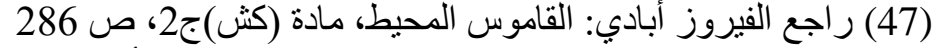
(48) راجع: الجو هري: تاج اللغة، وصحاح الفياح العربية، تحقيق: أحمد بن الغفور عطاء، ط4، دار العلم للملايين، بيروت، 1990م،

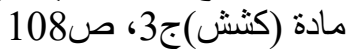

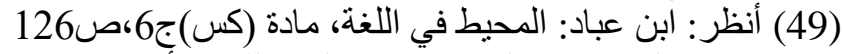

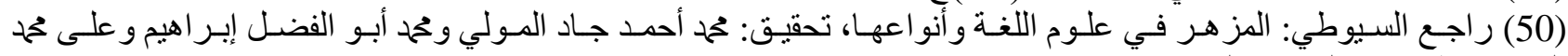

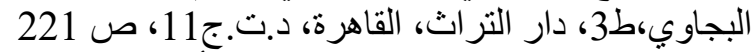

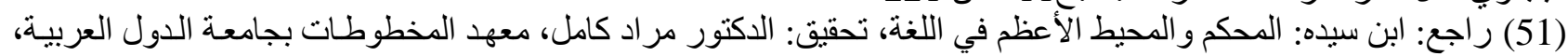

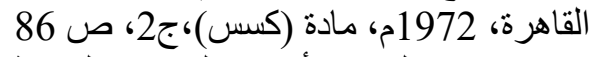

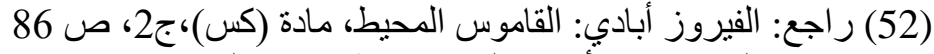

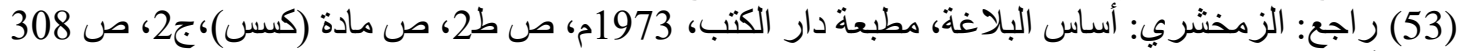

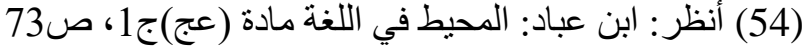

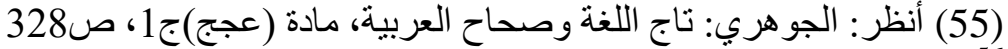

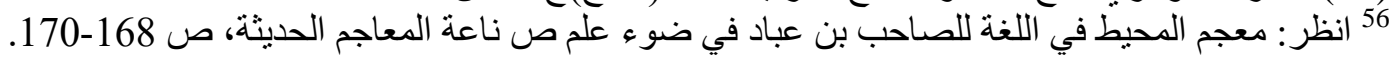




\begin{tabular}{|c|c|c|}
\hline 4 & أهل المدينة & 11 \\
\hline 4 & الروم & 12 \\
\hline 4 & النيس & 13 \\
\hline 4 & النبط & 14 \\
\hline
\end{tabular}

المبحث الثاني: منهج الصاحب في الاستشهاد الشواهد الشعرية وأقوال العرب: لقد استشهد ابن عباد بعدد كبير من الثواهد اهد الثعرية تزيد على عدد شو اهد القرآن الكريم و الحديثي

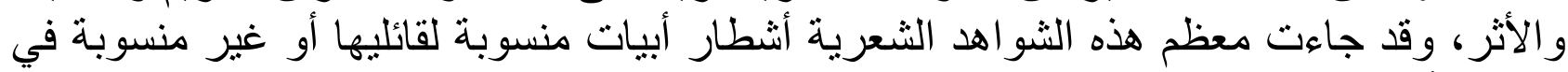
معظم الأحيان. و هنا سنذكر نماذج مختلفة توضح منهجه في توظيف الثاهد الثعري في المعجم.

\section{أ: أبيات شعرية كاملة منسوبة لقائليها:}

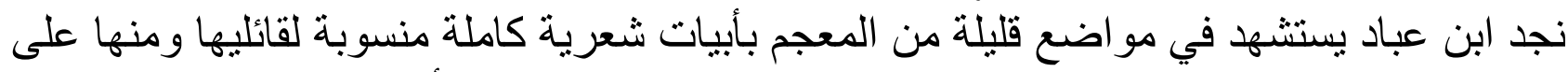
سبيل المثال: ورد في شرح مادة (عض) قوله: "والعضناض: عرنين الأنف في قول عياض بندرة:

و الجمه فأس الهو ان فلاكه *** و أغضى على غضغض أنض أنف مصلم (57). (الطويل) ورد في شرح مادة (وعث) قول ابن عباد: "و إمرأة وعثة الردف عجز اء، قال ابن هرمة: (الرمل):

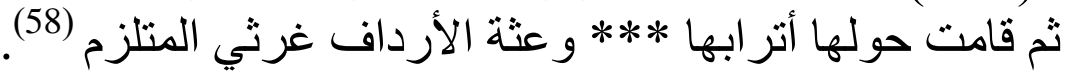
ورد في شرح مادة (صت) قول ابن عباد:" و الصتية: ملحفة من الماحف، وقيل: ثوب من أثواب

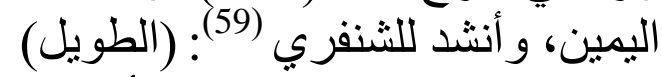

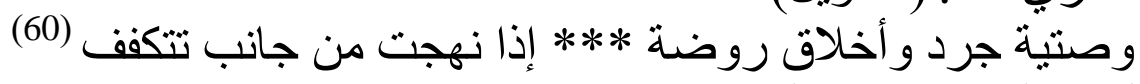
ب: أبيات شعرية كاملة غير منسوبة لخدافئليها استنهر ابن عباد في مواضع قليلة بأبيات شعرية كاملة غير منسوبة لقائليها ومنها على سبيل المثنال: في مادة (هدع) استشهد بييت شعري كامل غير منسوب لقائله (هدع):" الهودع: العنام، و أنشد:

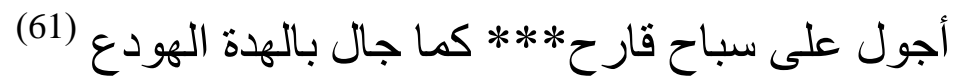
(المتقارب) (مادة) في موضع آخر نجده يمثل ببيت شعري كامل غير منسوب لقائله، فجاء في شرح مادة مادة (ضعف)

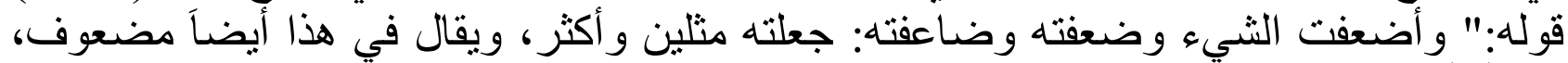

و عالين مضعوفاً وفرداً سموطة *** جمان ومرجان يثك المفاصلا (63) قال (62) (الطويل)

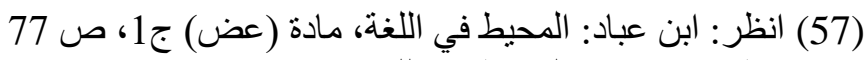

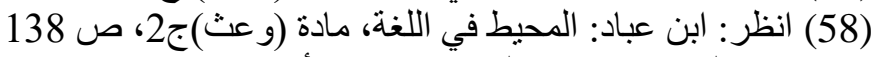

$$
\begin{aligned}
& \text { ورد البيت في ديوان الثنفري برو اية أخرى هي: }
\end{aligned}
$$

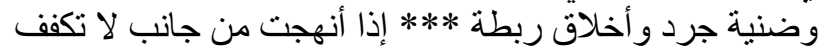

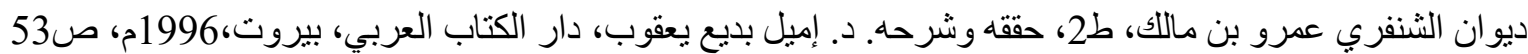

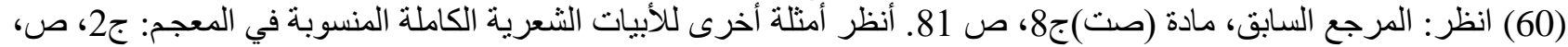

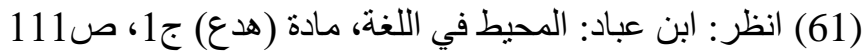

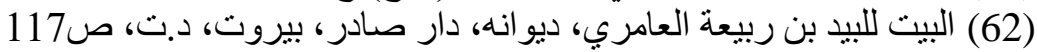

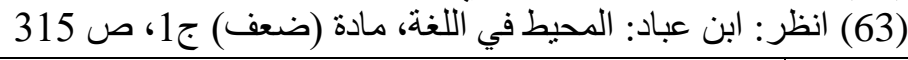




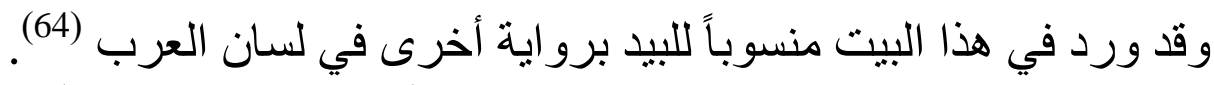

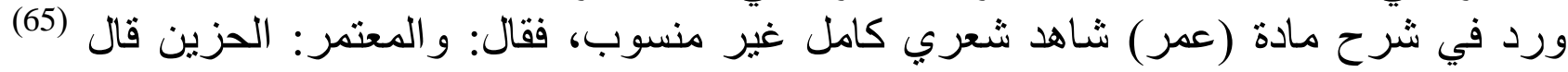

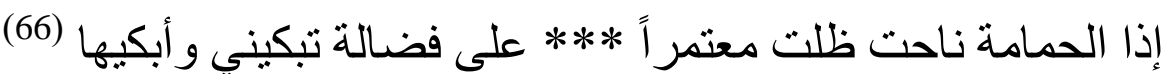
(البسيط): (البط

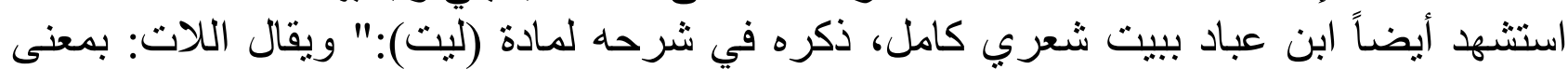
كأن طعم ريقها بالات ** ** ق قبيل أن تقوم للصلاة"(68)

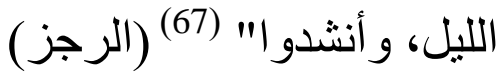

\section{ج: أشطار شعرية منسوبة لقائليها:}

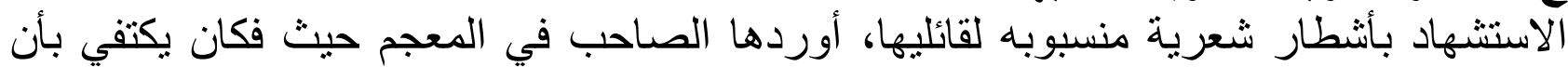

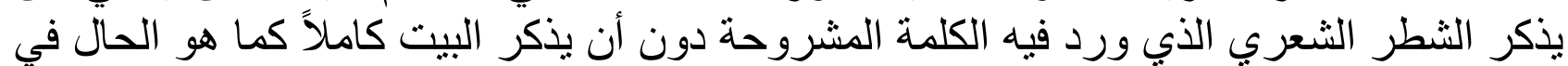

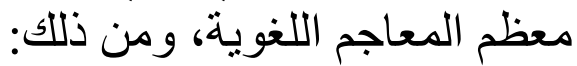

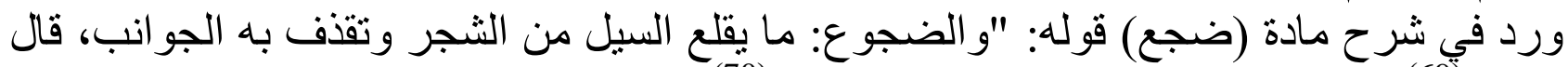

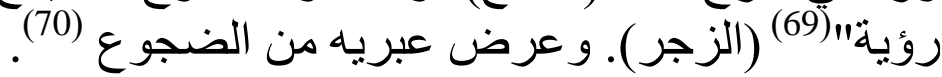

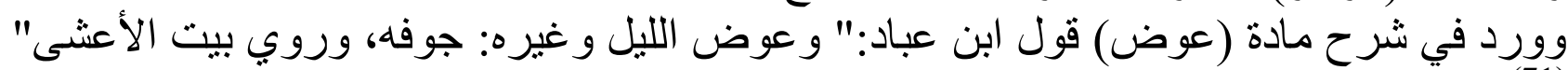
بأسحم داجي العوض لان نتقرق (72). واستشهد ابن منظور ببيت الأعشى كاملاً في مادة (عوض)

رضيعي لبان ثدي أم تحالفا**** بأسحم داج عوض لا ناد نتفرق (73).

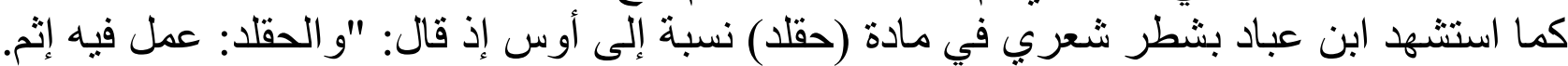

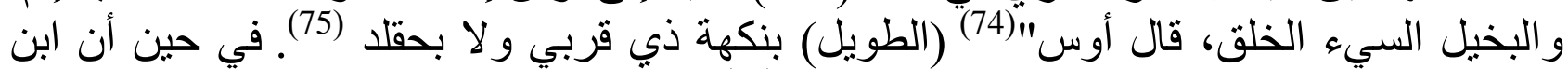

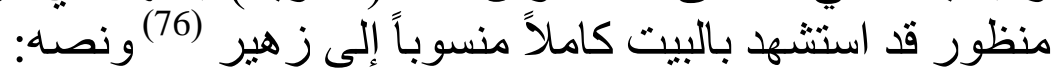

64) انظر : ابن منظور : لسان العرب، مادة (ضعف)ج5، ص 608 (65)

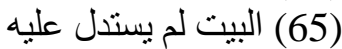

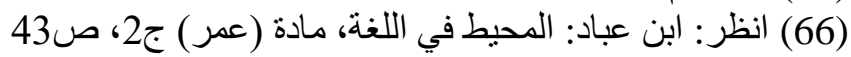

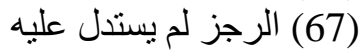

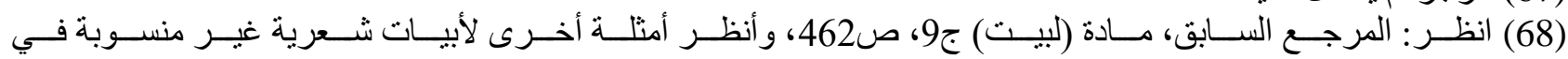

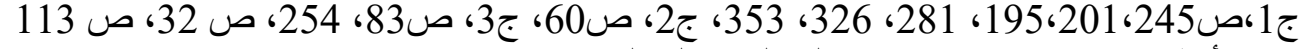

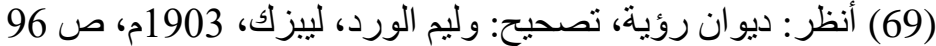

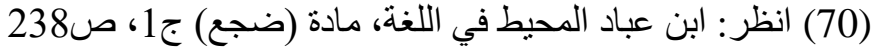

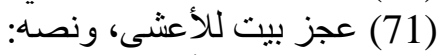

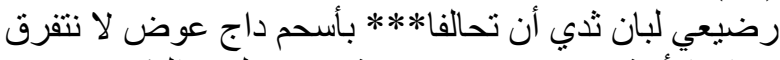

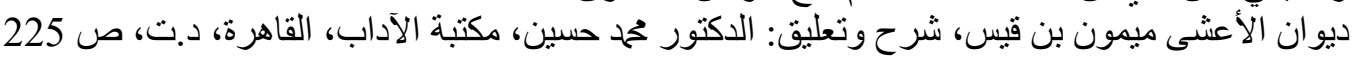

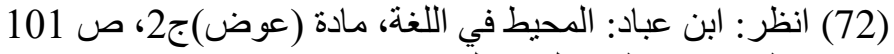

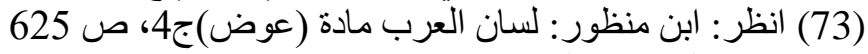

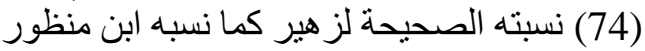

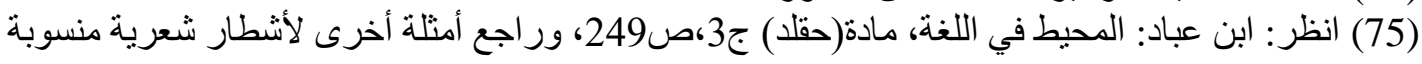

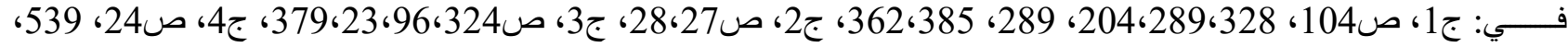

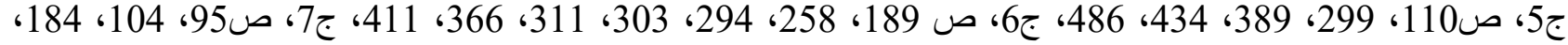
1912، 313، 324، ج8، ص 242 


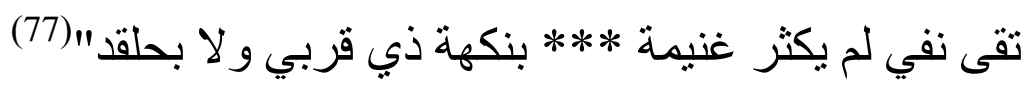

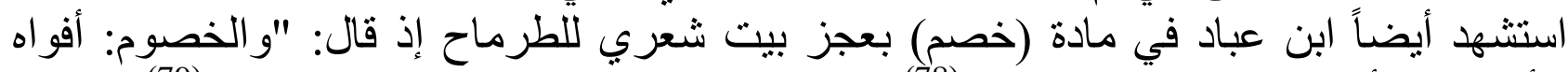

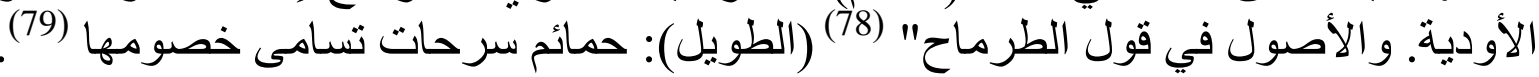

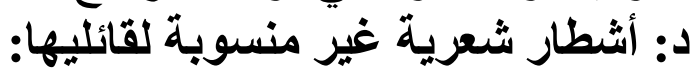

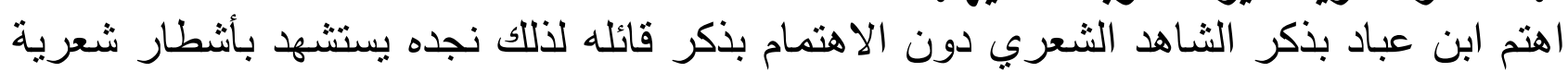

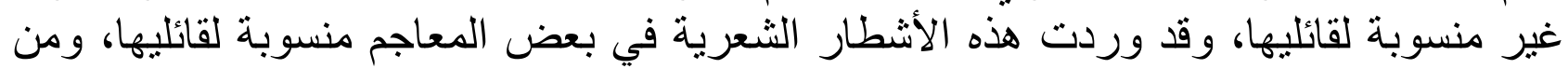
أمثلة ذلك في المعجم ما يلي: نجده في مادة (كمع) يستشهد بشطر بيت غير فئ منسوب إذ قال: "كامعها: ضاجعها وضمها إليه،

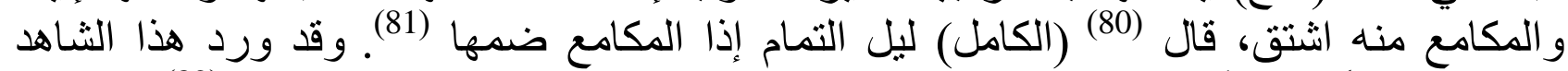
الثعري كاملاً منسوباً لذي الرمة في كتاب العين مادة (كمع) ونصهه:" قال ذو الرمة فيك" (82) (الكامل)

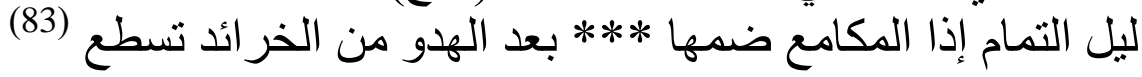

وورد في مادة (وحي) مشطور غير منسوب إذ قال: "وحي الهدو يحيى وحيا: كتب يكتب، وأنا

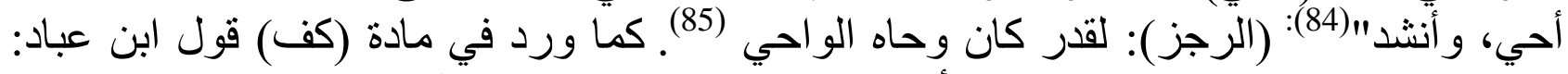
"و استكفقت الثيء: استوضحته؛ و هو أن تضع بدك على حاحبيك فتنظر إلى الثيء لثي لكي تستبينه،

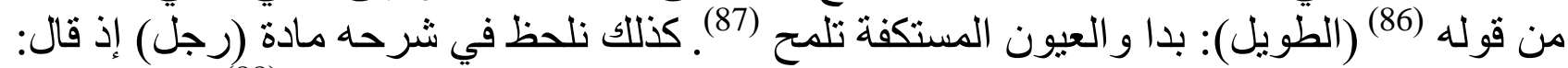
"و الرجل: جماعة الراجل؛ كالركب. وهم الرجالة الرجالة والرجال و الرجلة، وقوله (88) (المتقارب): فسقيت نسائي إلبكم رجالاً (89)

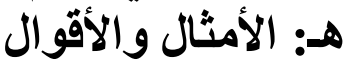

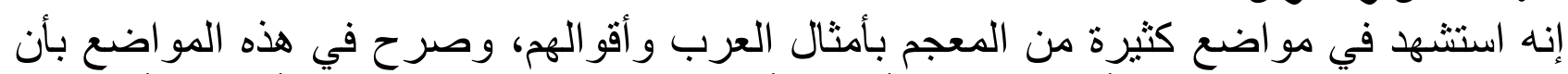
العبار ات المستشهد بها من أمثال العرب أو من أقو الهم، فيقول: (وفي المثل)، أو (من أمثالهم)،

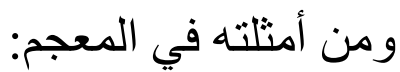
قال ابن عباد في شرح مادة (ثعل):" و الثعل: الثعلب: وثعالة يقال للذكر و الأنثى منها. وأرض

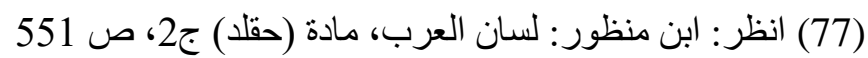

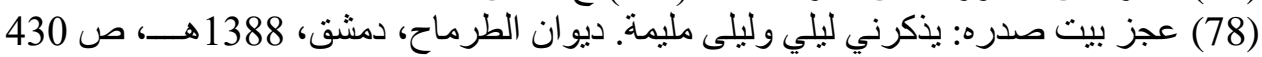

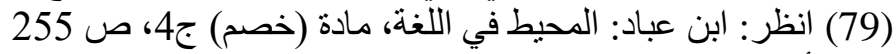

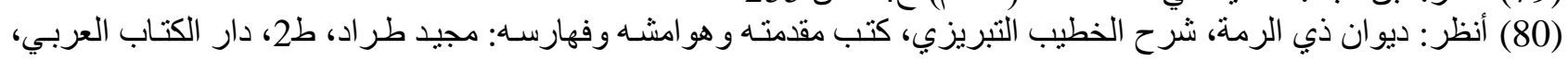

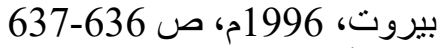

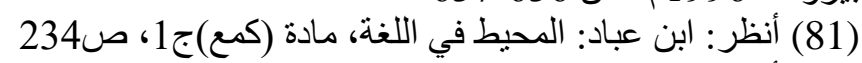

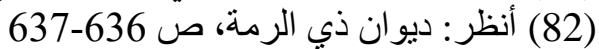

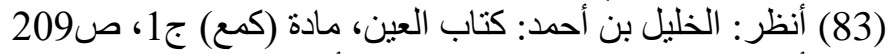

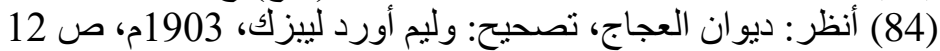

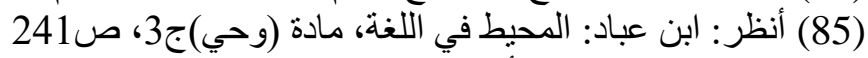

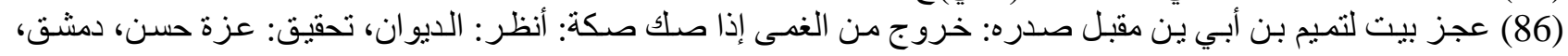

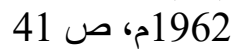

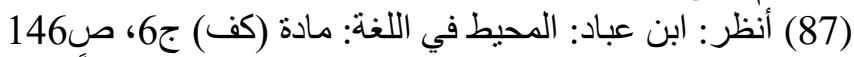

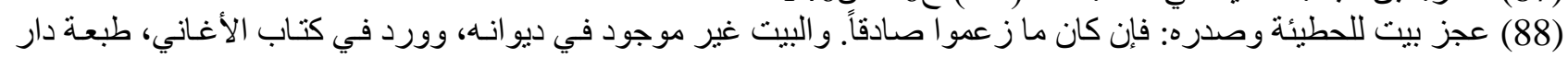

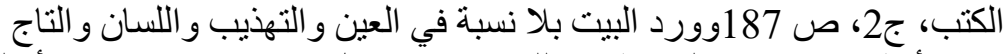

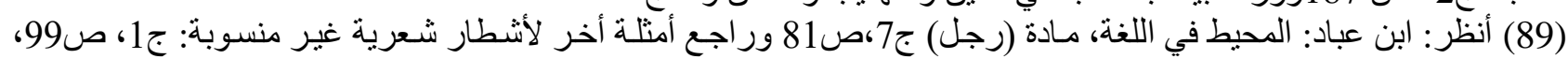

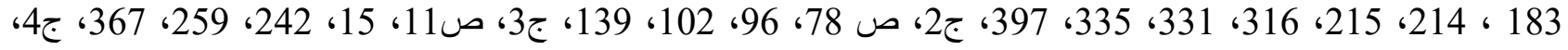

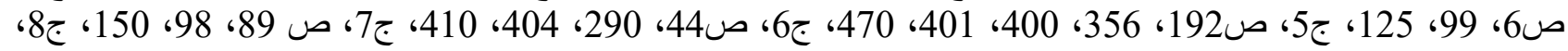

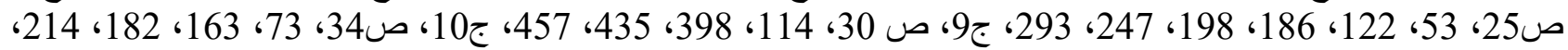
$.470 ، 461 ، 460 ، 240$ 
مثعلة: كثيرة الثعالي وفي المثل (90) "أعطش من ثعالة" وهي الذكر "(91). وقال في شرح مادة

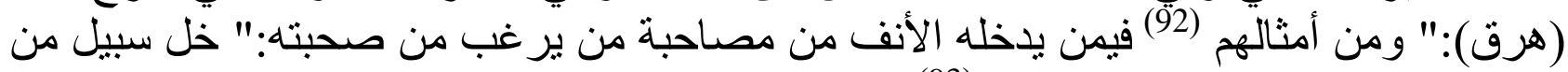

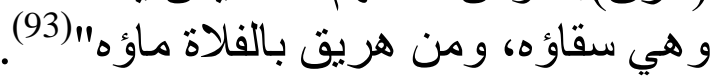

ونجد أحيانا أن ابن عباد لا يذكر أن العبارة المستشهد بها مثل من أمثال العرب كما فعل في في

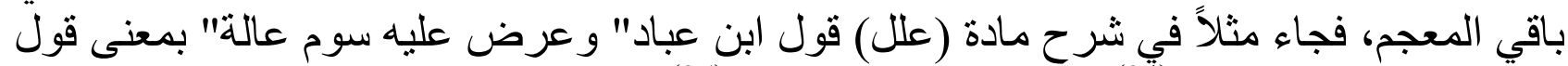

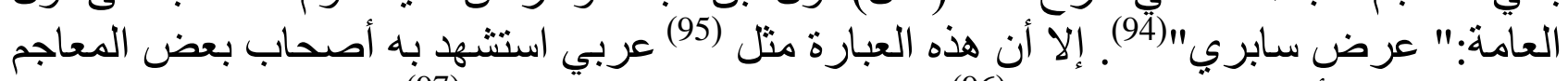

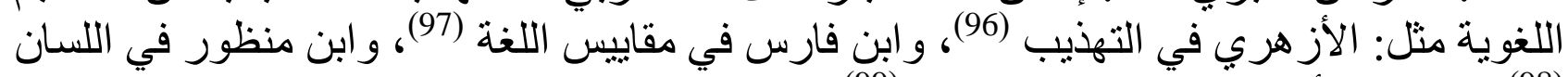

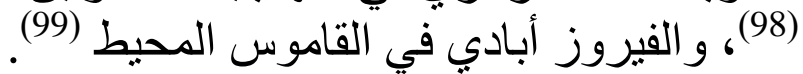
في الوقت نفسه وفي ثنائا مو اد المعجم نجد استشهاده ببعض أقو ال العرب المنسوبة لقائلبها أو غير منسوبة ويصرح بذلك عند الاستشهاد بها وعلى حين أننا نجد بعض هذه العبارات استشهد بها

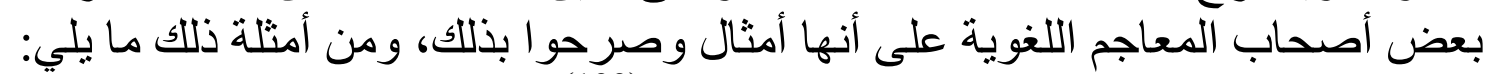

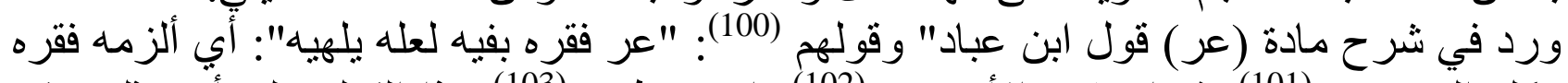

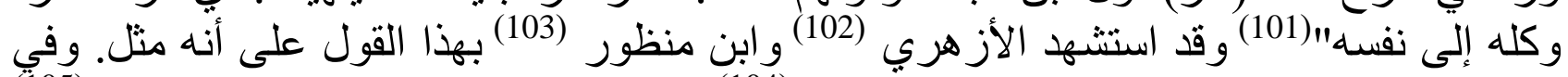

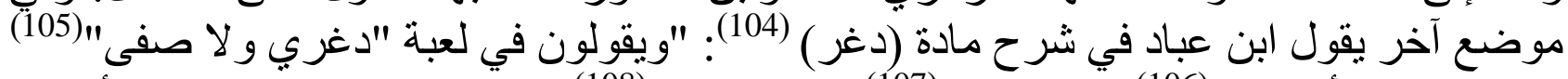

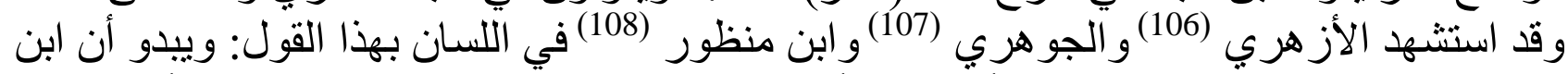

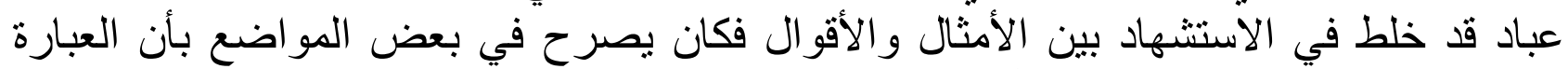

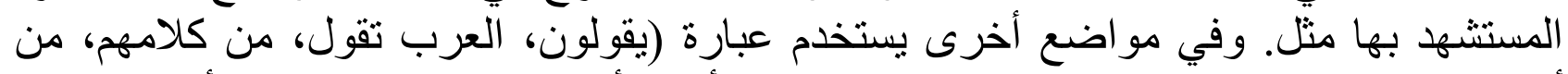

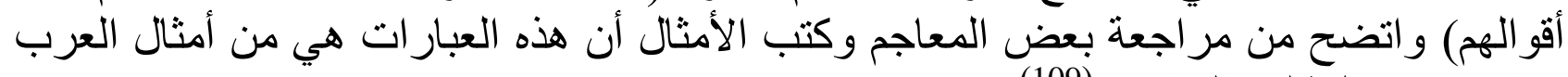

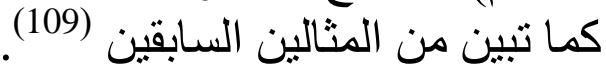

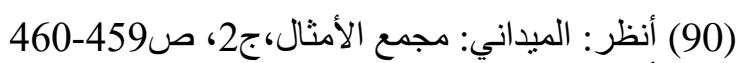

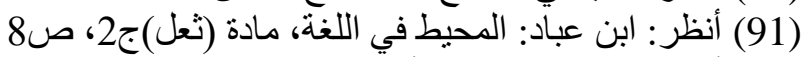

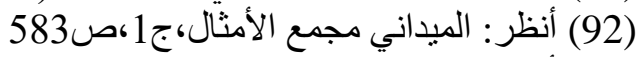

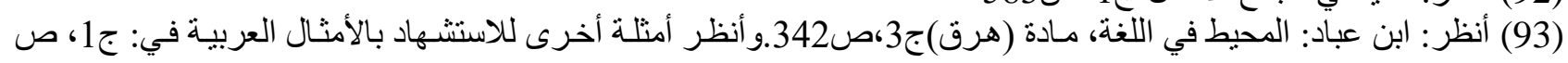

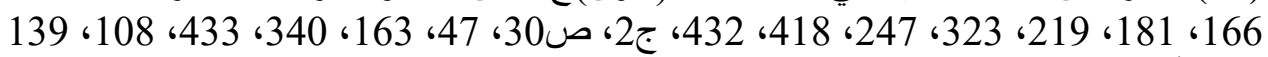

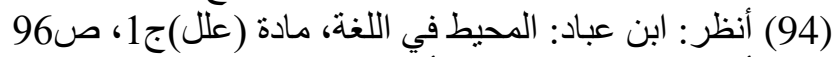

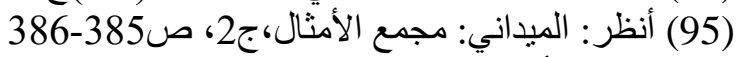

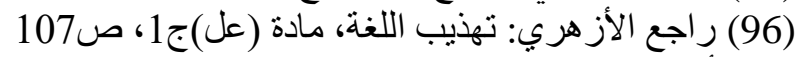

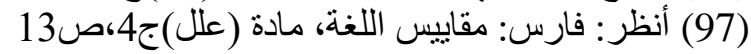

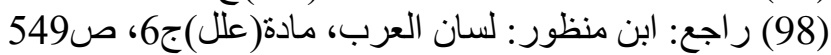

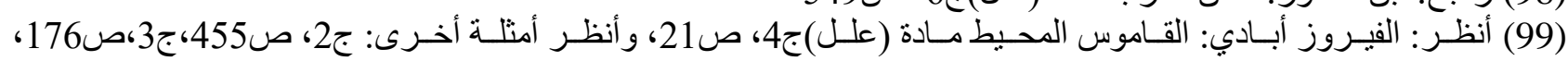

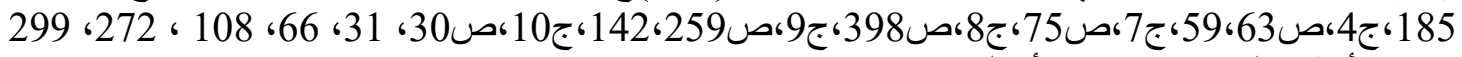

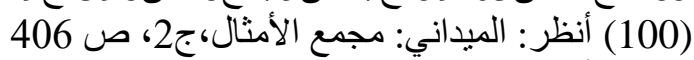

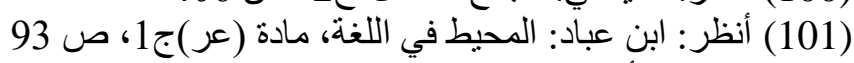

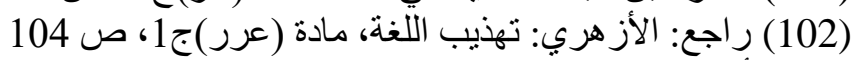

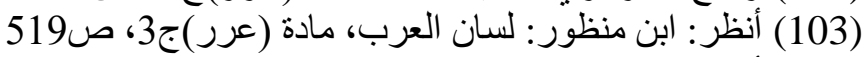

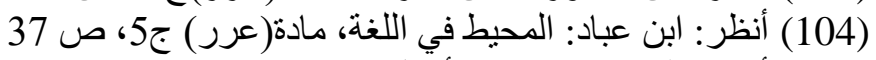

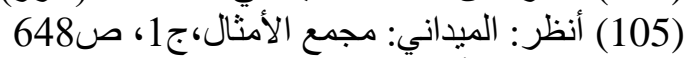

(106) راجع: الأز هري: نهذيب اللغة، مادة (دغر)جها،

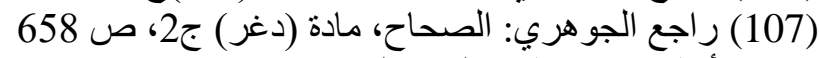

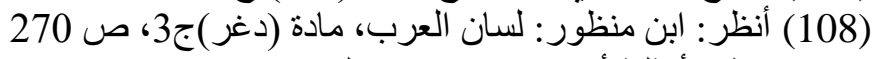

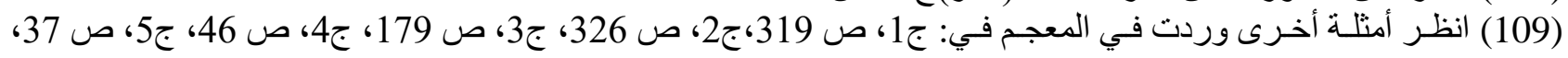

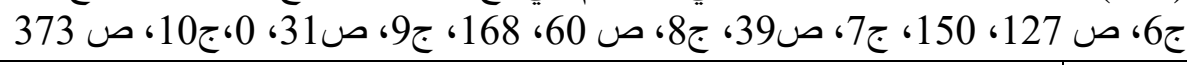




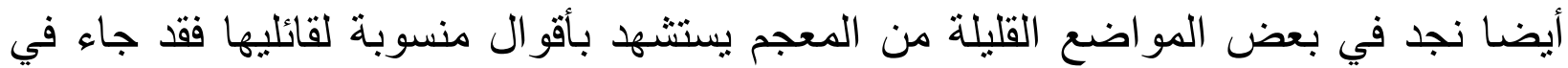

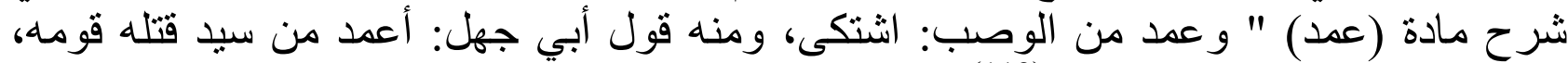

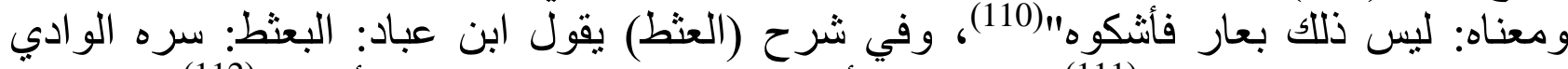

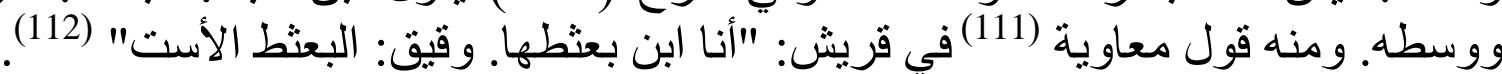

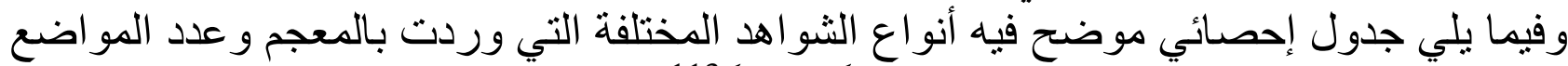
التي ورد فيها كل شاهد على إنى حدة مرنبة نرتبياً تناز لياً 113

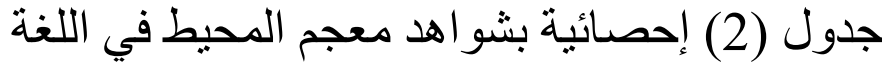

\begin{tabular}{|c|c|c|}
\hline عداد مرات ورودده في & نوع الثَاهد & ت تسلسل \\
\hline 1150 & الأمثنال العربية & 1 \\
\hline 432 & الأحاديث و الأقو ال المأثتورة & 2 \\
\hline 432 & أتشعار العرب & 3 \\
\hline 275 & الآيات القر آنبة & 4 \\
\hline 261 & اللغات و اللهجات & 5 \\
\hline 144 & أرجاز العرب & 6 \\
\hline
\end{tabular}

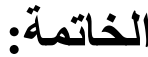

خلص البحث إلى عدد من النتائج من أهمها: أ. تعرض ابن عباد لذكر اللهجات العربية المختلفة خلال شروح الهوات الهواد مما يجعل للهجات العربية داخل معجم المحيط في اللغة كياناً يستحق الدر اسة و التحليل.

ب. استشهد الصاحب بن عباد خلال شرحه للمو اد للعديد من اللغات و اللهجات حيث كان أكثرها

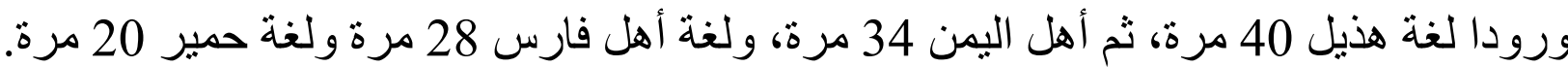
ت. قلل الصاحب بن عباد من الاستشهاد بالأشعار العربية مقارنة بمعظم المعاجم اللغوية التي كانت تكثر من الاستشهاد بالثُعر العربي.

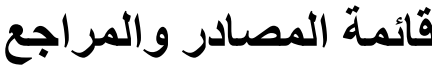

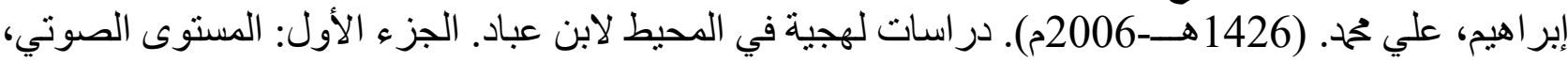
مجلة كلية اللغة العربية، العدد الر ابع و العشرون. ابن سيده، علي بن إسماعيل. (ت 458 هـ). المحكم و المحيط الأعظم في اللغة. تحقيق الدكتور مر اد كامل، معهد

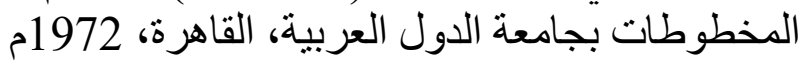

الأز هري، أبو منصور محمد بن أحمد (ت370). تهذيب اللغة. حققه وقدم له عبد السلام هارون، راجعه محمد علي

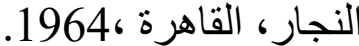


الجو هري، إسماعيل بن حماد (حو الي 400هـ). تاج اللغة وصحاح العربية. تحقيق أحمد بن الغفور عطاء، ط4، دار العلم للملايين، بيروت، 1990م.

ثعلب، أبو العباس. (1944م). شرح ديوان زهير بن أبي سلمى الزني. القاهرة: دار الكتب المصرية. الزمخشري، جار الله أبي القاسم محمود بن عمر (ت 538 هـ). أساس البلاغة. مركز تحقيق التراث، مطبعة دار الكتب، القاهرة، 1972.

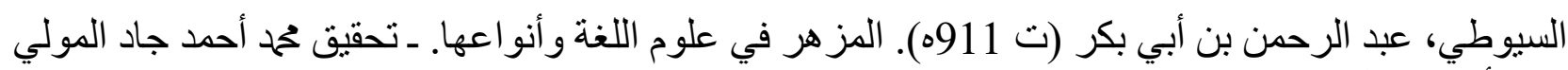

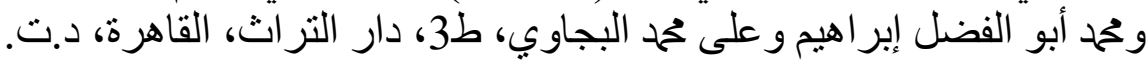
الميداني، أحمد بن محمد بن أحمد. (518 هـ). مجمع الأمثال. تحقيق جان عبد الله توما، دار صـادر، بيروت: 2002

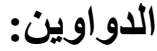

ديو ان الأعثى: ميمون بن قيس: شرح وتعليق: الدكتور حمح حسين، مكتبة الآداب، القاهرة، د.ت. ديو ان الثنفري: عمرو بن مالك، حققه وشرحه. د. إميل بديع يعقوب، دار الكتاب العربي، بيروت، ط2، 1996م. ديون.

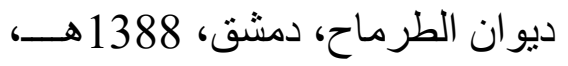
ديوان الهذليين، دار الكتب و الوثائق القومية، ط2، القاهرة، 1995م ديوان امرئ القبس، تحقيق: ححمد أبو الفضل إبر اهيم، القاهرة: دار المعارف. ديوان ذي الرمة، شرح الخطيب التبريزي، كتب مقدمته وهو امشه وفهارسه: مجيد طر اد، دار الكتاب العربي،

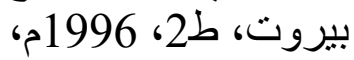
العين: الخليل بن أحمد الفر اهيدي:( 175 هـ)، تحقيق: د. مهدي المخزومي و إبر اهيم السامر ائي، دار الرشبد، بغداد 1980م. القاموس المحيط: الفيروز آبادي: ححمد بن يعقوب (ت 817 هـ)، المطبعة الأميرية، القاهرة، 1933م. لسان العرب: ابن منظور : جمال الدين محمد بن مكرم الأنصاري الأفريقي المصري (ت

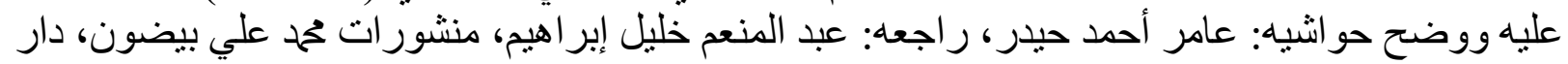

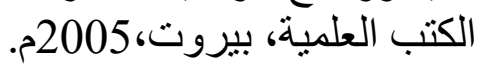

المحيط في اللغة: الصاحب بن عباد: كافي الكفاة الصاحب إسماعيل بن عباد (ت 385 هـ)، تحقيق: الثيخ حمح

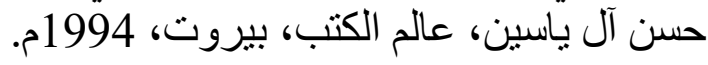
معجم القراءات: عبد اللطيف الخطيب، دار سعد الدين، د.ت، معجم المحيط في اللغة للصاحب بن عباد في ضوء علم علم صناعة المعاجم الحديثة: ابتهال أحمد صلاح، دار الكتب و الوثائق القومية، القاهرة، ط1، المجة 2014م. معجم مقاييس اللغة ابن فارس: أبو الحسن أحمد بن فارس بن زكريا (ت 395 هـ) تحقيق وشرح: عبد السلام

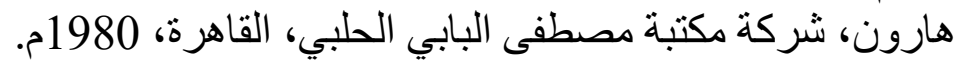




\section{ARABIC REFERENCES IN ROMAN ALPHABET}

'librahim, Eali Mahmad. (1426ha-2006ma). Dirasat Lihjiat fi Almuhit Liaibn Eibad. Aljuz' Al'awla: Almustawaa Alsawtii, Majalat Kuliyat Allughat Alearabiati, Aleadad Alrrabie Waleashurun.

Abn Sayiduhu, Eali Bin 'lismaeil. (T 458 H). Almuhkam Walmuhit Al'aezam fi Allgha. Tahqiq Alduktur Murad Kamil, Maehad Almakhtutat Bijamieat Alduwal Alearabiati, Alqahirati, 1972m

Al'azhariu, 'Abu Mansur Muhamad Bin 'Ahmad (T370). Tahdhib Allaghati. Haqaqah Waqadam Lah Eabd Alsalam Harunu, Rajieuh Muhamad Eali Alnajar, Alqahrt ,1964.

Aljawhari, 'lismaeil Bin Hammad (Hwali 400h). Taj Allughat Wasahah Alearabiati. Tahqiq 'Ahmad Bin Alghafur Eata', T4, Dar Aleilm Lilmalayin, Bayruut, 1990m.

Thaealab, 'Abu Aleabasa. (1944ma). Sharah Diwan Zahir Bin 'Abi Sulamaa Alzini. Alqahirat: Dar Alkutub Almisriat.

Alzamkhishriu, Jar Allah 'Abi Alqasim Mahmud Bin Eumar (T $538 \mathrm{Ha}$ ). 'Asas Albalaghat. Markaz Tahqiq Altarathi, Mutbaeat Dar Alkutub, Alqahirat, 1972. Alsayuti, Eabd Alruhmin Bin 'Abi Bikr (T 911h).

Almazhar Fi Eulum Allughat Wa'anwaeha. Tahqiq Muhamad 'Ahmad Jad Almawli Wamuhamad 'Abu Alfadl 'librahim Waealaa Muhamad Albjawy, T3, Dar Altarathu, Alqahirat, Da.T. Almidani, 'Ahmad Bin Muhamad Bin 'Ahmad. (518 Ha).

Majmae Al'amthal. Tahqiq Jan Eabd Allah Tuma, Dar Sadir, Birut: 2002m.

Diwan Al'aeshaa: Maymun Bin Qis: Sharah Watelyq: Alduktur Muhamad Husayn, Maktabat Aladab, Alqahirat, da.t.

Diwan Alshanafri: Eamrw Bin Malik, Haqaqah Washarhuh. Da. 'limil Badie Yaequb, Dar Alkitab Alearabii, Bayruut, t2, 1996m.

Diwan Altarmahi, Dimashq, 1388h,

Diwan Alhadhaliiyna, Dar Alkutub Walwathayiq Alqawmiatu, T2, Alqahirat, 1995m

Diwan Amri Alqis, Tahqiq: Muhamad 'Abu Alfadl 'librahim, Alqahirata: Dar Almearf. Diwan Dhi Alrimati, Sharah Alkhatib Altabrizi, Kutib Muqadimatah Wahawamishah Wafaharisuh: Majid Taradi, Dar Alkitab Alearabii, Bayrut, t2, 1996m,

Aleayna: Alkhalil Bin 'Ahmad Alfrahydy:( $175 \mathrm{Ha}$ ), Tahqiq: D. Mahdi Almakhzumi Wa'iibrahim Alsamrayy, Dar Alrshid, Baghdad 1980m.

Alqamus Almhyt: Alfiruz Abadi: Muhamad Bin Yaequb (T $817 \mathrm{Ha}$ ), Almutbaeat Al'amiriat, Alqahirat, 1933m.

Lisan Aleurba: Abn Manzur: Jamal Aldiyn Muhamad Bin Mukrim Al'ansarii Al'afriqii Almisrii (T 711h), Haqaqah Waealaq Ealayh Wawadh Hawashyh: Eamir 'Ahmad Haydr, Rajieh: Eabd Almuneim Khalil 'librahim, Manshurat Muhamad Eali Bidun, Dar Alkutub Aleilmiat, Birut,2005m.

Almuhit Fi Allght: Alsaahib Bin Eabad: Kafi Alkufat Alsaahib 'lismaeil Bin Eibad (T 385 H), Thqyq: Alshaykh Muhamad Hasan Al Yasin, Ealam Alkatub, Bayrut, 1994m.

Muejim Alqara'at: Eabd Allatif Alkhatib, Dar Saed Aldiyn, Da.T,

Maejim Almuhit Fi Allughat Lilsahib Bin Eibad Fi Daw' Eilm Sinaeat Almueajim Alhdytht: Aibtihal 'Ahmad Salah, Dar Alkutub Walwathayiq Alqawmiat, Alqahirat, T1, 2014m.

Maejam Maqayis Allughat Abn Farsa: 'Abu Alhasan 'Ahmad Bin Faris Bin Zakariaa (T 395 Ha) Tahqiq Washarh: Eabd Alsalam Harun, Sharikat Maktabat Mustafaa Albabi Alhalbi, Alqahirat, 1980m. 